\title{
Atypical Appearance of Hepatocellular Carcinoma and Its Mimickers: How to Solve Challenging Cases Using Gadoxetic Acid-Enhanced Liver Magnetic Resonance Imaging
}

\author{
Jae Hyun Kim, $M D^{1,2}$, Ijin Joo, $M D^{1,2}$, Jeong Min Lee, $M D^{1,2,3}$ \\ ${ }^{1}$ Department of Radiology, Seoul National University Hospital, Seoul, Korea; ${ }^{2}$ Department of Radiology, Seoul National University College of \\ Medicine, Seoul, Korea; ${ }^{3}$ Institute of Radiation Medicine, Seoul National University Medical Research Center, Seoul, Korea
}

Hepatocellular carcinoma (HCC) can be diagnosed noninvasively with contrast-enhanced dynamic computed tomography, magnetic resonance imaging, or ultrasonography on the basis of its hallmark imaging features of arterial phase hyperenhancement and washout on portal or delayed phase images. However, approximately $40 \%$ of HCCs show atypical imaging features, posing a significant diagnostic challenge for radiologists. Another challenge for radiologists in clinical practice is the presentation of many HCC mimickers such as intrahepatic cholangiocarcinoma, combined HCC-cholangiocarcinoma, arterioportal shunt, and hemangioma in the cirrhotic liver. The differentiation of HCCs from these mimickers on preoperative imaging studies is of critical importance. Hence, we will review the typical and atypical imaging features of HCCs and the imaging features of its common mimickers. In addition, we will discuss how to solve these challenges in practice.

Keywords: Atypical hepatocellular carcinoma; Hepatocellular carcinoma mimickers; Intrahepatic mass-forming cholangiocarcinoma; Combined hepatocellular-cholangiocarcinoma; Liver Imaging Reporting and Data System

\section{INTRODUCTION}

Hepatocellular carcinoma (HCC) is the most common primary hepatic malignancy and the second leading cause of cancer-related death worldwide $(1,2)$. It typically originates from the cirrhotic liver $(3,4)$, with $2-8 \%$ of cirrhosis patients developing HCC each year (5). Recent guidelines, including those of the European Association for the Study of the Liver and European Organization for Research and Treatment of Cancer (EASL-EORTC), the American

Received September 11, 2018; accepted after revision March 17, 2019.

Corresponding author: Jeong Min Lee, MD, Department of Radiology, Seoul National University College of Medicine, 101 Daehak-ro, Jongno-gu, Seoul 03080, Korea.

- Tel: (822) 2072-3154 - Fax: (822) 743-6385

-E-mail:jmsh@snu.ac.kr

This is an Open Access article distributed under the terms of the Creative Commons Attribution Non-Commercial License (https://creativecommons.org/licenses/by-nc/4.0) which permits unrestricted non-commercial use, distribution, and reproduction in any medium, provided the original work is properly cited.
Association for the Study of Liver Disease (AASLD), and the Korean Liver Cancer Study Group and the National Cancer Center (KLCSG-NCC), allow for the noninvasive diagnosis of HCC using contrast-enhanced computed tomography (CT), magnetic resonance imaging (MRI), or ultrasonography (US) on the basis of its typical imaging features $(2,6-9)$. The hallmark imaging features of HCC are arterial phase hyperenhancement (APHE) and portal/delayed washout, which represent the characteristic vascular profile of $\mathrm{HCC}$ on dynamic CT or MRI (8-11). However, approximately $40 \%$ of $\mathrm{HCCs}$ do not demonstrate these imaging findings, resulting in a low sensitivity of imaging tests for the diagnosis of HCC (12). Indeed, these HCCs with atypical imaging features remain a huge diagnostic challenge for radiologists today. Moreover, in at-risk patients, there can be many $\mathrm{HCC}$ mimickers such as intrahepatic cholangiocarcinoma (ICC), combined HCC-cholangiocarcinoma (CHCC-CC), arterioportal (AP) shunt, and hemangioma. Therefore, precise differentiation of $\mathrm{HCCS}$ from these mimickers on preoperative imaging studies would be of great clinical 
importance, guiding the appropriate treatment strategy.

In this article, we will review the typical and various atypical imaging features of HCCs as well as the imaging features of its mimickers on dynamic CT and MRI, and then discuss how we may solve these challenging cases in clinical practice.

\section{Typical Imaging Features of HCC}

The typical imaging features of HCC mainly originate from the histopathologic characteristics of nodular progressed HCCS rather than those of early HCCs. Among the many pathophysiologic alterations that may occur during hepatocarcinogenesis, neovascularization is the most important component that helps to provide the characteristic imaging features of progressed HCCs (13). Progressed HCCs receive their blood supply from unpaired arteries rather than portal veins (14), and venous drainage occurs through the portal veins rather than the hepatic veins (15). Therefore, on dynamic CT and MRI, progressed HCCs typically show APHE followed by washout appearance on the portal or delayed phases (Fig. 1). According to the Liver Imaging Reporting and Data System (LI-RADS), APHE is defined as relative hyperenhancement in comparison with the surrounding liver parenchyma, and washout is defined as a non-peripheral, visually assessed temporal reduction in the degree of enhancement relative to composite liver tissue, resulting in hypoenhancement in the portal venous or delayed phases (16). To the contrary, however, early HCCs commonly show hypovascularity on dynamic $\mathrm{CT}$ and MRI owing to insufficient neovascularization and decreased portal blood supply (17).

HCCs can also show several other characteristic imaging features that may be helpful in their differentiation from other benign liver lesions (Fig. 1). First, tumor capsules are observed in approximately $70 \%$ of progressed HCCs with expansile growth $(18,19)$. The capsule appearance is defined as a peripheral rim enhancement observed in the portal venous or delayed phases of contrast-enhanced CT or MRI (13). This capsular appearance should be differentiated from rim enhancement that is only seen in the arterial phase, which is common in cholangiocarcinoma (CC) or metastases from adenocarcinoma.

The nodule-in-nodule architecture is another characteristic histologic and radiologic feature of HCC. It is defined as the presence of a smaller inner nodule with

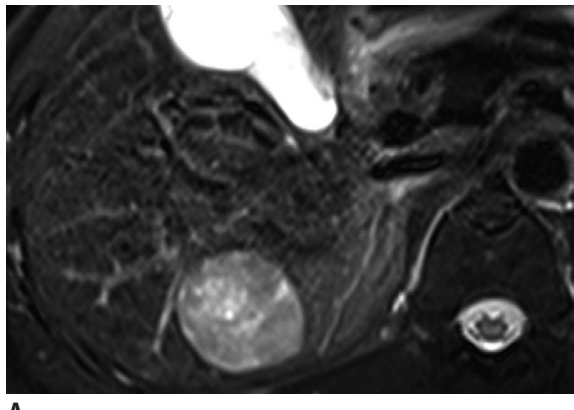

A

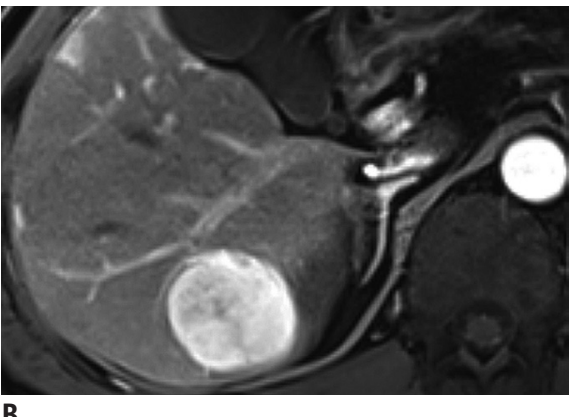

B

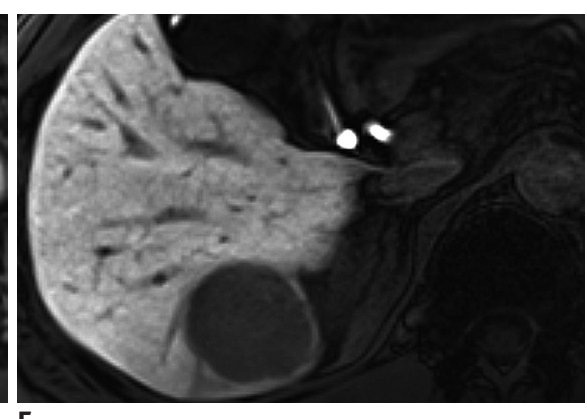

E

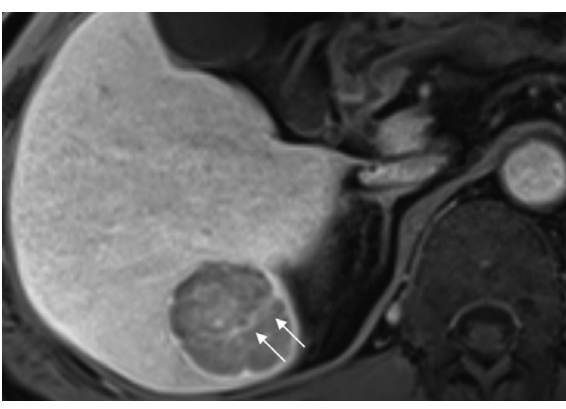

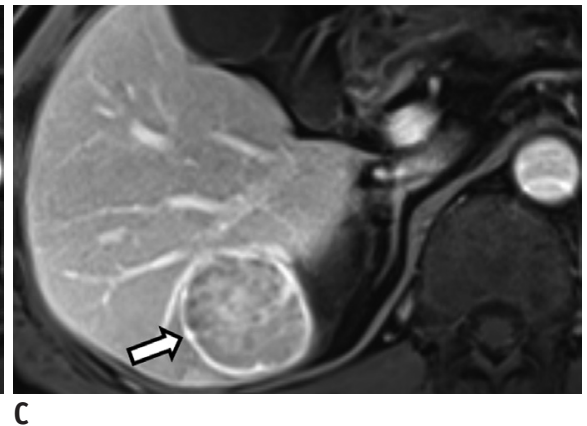

C

Fig. 1. 50-year-old man with HCC and hepatitis B-related cirrhosis.

(A) T2WI shows hyperintense mass in segment VI of liver. Mass shows hyperenhancement on (B) arterial phase image and definite washout on (C) portal venous and (D) transitional phase images of gadoxetic acid-enhanced liver MRI. Capsule appearance (arrow), internal septum (thin arrows), and mosaic architecture are also noted on portal venous and transitional phase images. (E) Mass is hypointense on $\mathrm{HBP}$ image. $\mathrm{HBP}=$ hepatobiliary phase, $\mathrm{HCC}=$ hepatocellular carcinoma, T2WI = T2-weighted imaging 
different imaging features from the larger outer nodule, suggesting the presence of a progressed $\mathrm{HCC}$ portion within a dysplastic nodule (DN) or an early HCC (20). Similarly, the mosaic architecture is also an important characteristic imaging feature of large HCCs. This imaging feature refers to the presence of randomly distributed internal nodules or compartments usually separated by fibrous septations, showing different attenuation, signal intensity (SI), and enhancement pattern $(21,22)$ (Fig. 1). Vascular invasion is also common in large and/or high-grade HCCs, and thrombosis in the portal vein is reported to occur in 44-62.8\% of large HCCs (23). A tumor thrombus can be identified by its contiguity with the primary tumor and shows a tendency toward an expansile feature, enlargement of thrombosed vessels, and increased neovascularity, resulting in contrast enhancement (24).

Furthermore, during hepatocarcinogenesis, increased cell density and small cell changes are inevitable processes that result in T2 high SI and diffusion restriction on MRI (25). Fat accumulation within tumors also occurs during hepatocarcinogenesis, although the intralesional fat component is most frequently observed in early HCCs rather than in progressed HCCs (26). In this regard, T1-weighted gradient echo imaging or chemical shift imaging may detect this intralesional fat more sensitively than CT (13). Organic anion transporting polypeptide (OATP) expression, on the other hand, gradually decreases as a nodule progresses from a cirrhotic nodule to a progressed HCC (13). Thus, many high-grade DNs and HCCs show low SI on the hepatobiliary phase (HBP) of gadoxetic acid-enhanced MRI owing to this decreased expression of $\operatorname{OATP}(27,28)$.

In many major guidelines, APHE and washout on portal or delayed phase are considered to be essential for a noninvasive diagnosis of HCC on either contrast-enhanced CT or MRI (8-11). However, for gadoxetic acid-enhanced MRI, the diagnostic criteria for HCC are slightly different across these guidelines: the AASLD, EASL-EORTC, and LI-RADS guidelines recommend that washout should be determined on the portal venous phase while the Asian Pacific Association for the Study of the Liver (APASL) and KLCSG-NCC guidelines permit HBP hypoenhancement as an alternative sign to washout. This discrepancy mainly stems from the different designs of HCC imaging systems across various geographic areas (29): in Europe and North America, the diagnostic criteria are intentionally designed to achieve high specificity rather than high sensitivity for the diagnosis of a definite $\mathrm{HCC}$ while diagnostic criteria in Asia pursue high sensitivity for the detection of HCCs $(10,30)$.

\section{HCCs with Atypical Imaging Features}

\section{Non-Hypervascular HCCs}

One of the problematic diagnostic challenges that radiologists face today is the non-hypervascular hepatic nodule detected in at-risk patients $(9,31)$. Considering the multistep hepatocarcinogenesis, most DNs and early HCCs tend to show hypovascularity on dynamic imaging studies due to decreased portal supplies and insufficient neovascularization $(13,28)$ (Fig. 2). The international consensus group for HCC (17) and the World Health Organization (32) defines an "early $\mathrm{HCC}^{\text {" as a cancer }}$ composed of well-differentiated tumor cells $<2 \mathrm{~cm}$ in size, with poorly defined margins, and of the vaguely nodular type. Early HCCs also show more favorable biologic features at pathologic examination and have a lower risk for recurrence after treatment than small progressed HCCs (13, 33). Therefore, it is imperative to detect and treat early HCCs in at-risk patients before they become progressed HCCs (34).

Although early HCCs may more frequently show APHE and washout on dynamic imaging studies and low SI on the HBP of gadoxetic acid-enhanced MRI compared to DNs, these features alone would be insufficient to accurately differentiate early HCCs from DNs (28). Nevertheless, several studies have reported that ancillary features such as size larger than $15 \mathrm{~mm}$, low SI on T1-weighted imaging (T1WI), high SI on T2-weighted imaging (T2WI), and diffusion restriction on diffusion-weighted imaging (DWI) may improve radiologists' diagnostic accuracy in distinguishing early HCCs from DNs $(22,26,35)$ (Fig. 2). In particular, in hypovascular nodules with low SI on the HBP, diffusion restriction on DWI was shown to be strongly related to progression to hypervascular HCCs within a few years (36).

\section{HCCs with the Targetoid Appearance}

The targetoid appearance refers to a target-like morphology that reflects peripheral hypercellularity and central fibrosis or ischemia within the tumor (21). On imaging studies, the peripheral enhancement of tumors is determined by either the amount of the fibrotic component within the tumors or central necrosis/ischemia in more aggressive tumors (37). Among the HCC variants, those with more fibrotic components than classical HCCs include HCCs expressing stemness-related markers and scirrhous HCCs (38). On the other hand, central 


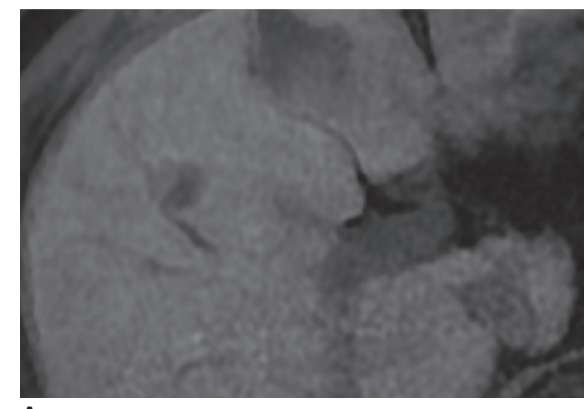

A

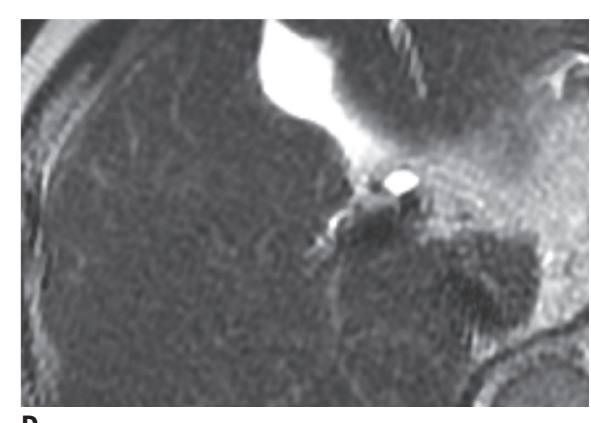

D

Fig. 2. 55-year-old man with early HCC and hepatitis B-related cirrhosis.

Nodule in segment $V$ of liver is hypointense relative to adjacent liver parenchyma on (A) precontrast T1WI. Nodule shows no definite enhancement on (B) arterial phase image. Nodule is heterogeneous but mostly hypointense on (C) HBP image and isointense on (D) T2WI. Lesion (arrows) shows hyperintensity on (E) DWI $\left(b=800 \mathrm{sec} / \mathrm{mm}^{2}\right)$ and hypointensity on (F) apparent diffusion coefficient map, suggesting restricted diffusion. DWI $=$ diffusion-weighted imaging, T1WI= T1-weighted imaging

ischemia or necrosis in biologically aggressive tumors such as poorly differentiated HCCs or sarcomatoid HCCs may also result in the targetoid appearance (39-41). In addition, large HCCs $(\geq 5 \mathrm{~cm})$ also frequently show the targetoid appearance on imaging studies due to heterogeneous internal contents, including necrotic content $(42,43)$.

Scirrhous HCCs, in particular, show even more fibrotic components than HCCs expressing stemness-related markers on pathologic examinations. Interestingly, according to recent studies, both HCCs expressing stemness-related markers and scirrhous HCCs were shown to frequently express many hepatic stem/progenitor cell (HPC) markers such as keratin 19, cluster of differentiation 133, and epithelial cell adhesion molecule $(44,45)$. In addition, these HPC markers are now considered to be involved in the fibrogenesis of the tumor $(45,46)$ and the aggressive tumor behavior including microvascular invasion, infiltrative growth, and poor prognosis $(44,45)$. Recent pathologic studies have suggested that HCCs expressing stemness-related markers, scirrhous HCCs, and CHCC-CCs may be located somewhere between $\mathrm{HCC}$ and $\mathrm{CC}$ if primary hepatic malignancies were classified according to cellular differentiation (47-49).

As for its radiologic features, according to a recent study by Jeong et al. (50), HCCs expressing stemness-related markers showed nonexpanding morphology on dynamic MRI, along with a persistent or progressive enhancement pattern, less frequent nodule-in-nodule appearances, and higher SI on DWI compared to classical HCCs. Furthermore, on gadoxetic acid-enhanced MRI, HCCs expressing stemnessrelated markers more frequently showed hyperintensity on DWI and hypointensity on the HBP compared to HCCs that did not express stemness-related markers (50).

Scirrhous HCCs, on the other hand, frequently show peripheral rim-like contrast enhancement on arterial and portal phases and prolonged delayed enhancement of the central region on dynamic CT and MRI (Fig. 3) $(46,51,52)$. Although the targetoid appearance on the HBP defined as peripheral low SI compared to the central portion is a common imaging feature of ICC, approximately $80 \%$ of scirrhous HCCs also showed this characteristic feature (53). Nevertheless, it is critical to distinguish scirrhous HCCs from ICCs on preoperative imaging since the respective treatment strategies are vastly different. In this regard, Choi et al. (54) proved in their study that the presence of T2 central darkness, a capsule, and septum on MRI are statistically significant features of scirrhous HCCs in comparison with ICCs (Fig. 3). Furthermore, Park et al. (53) demonstrated 


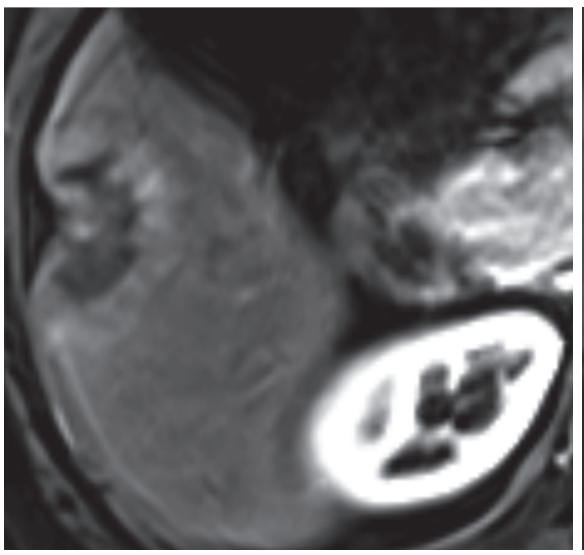

A

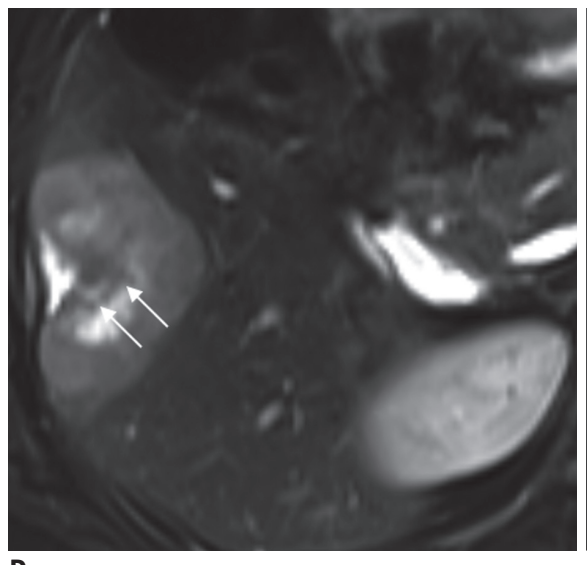

D

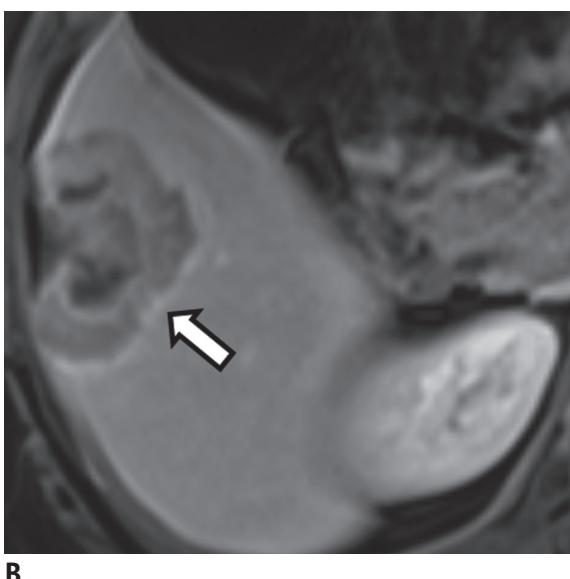

B

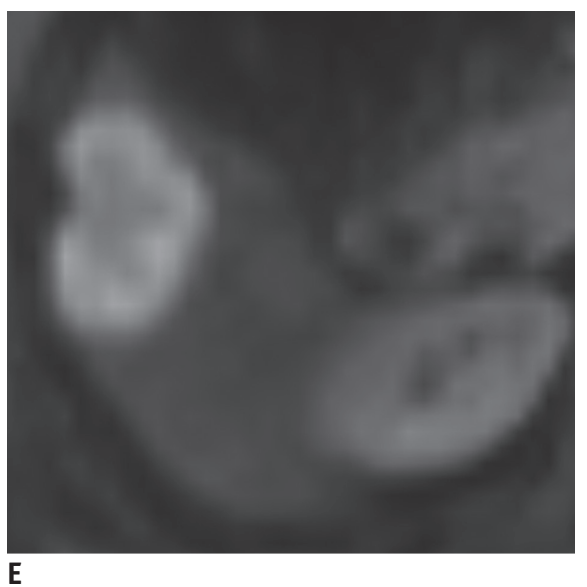

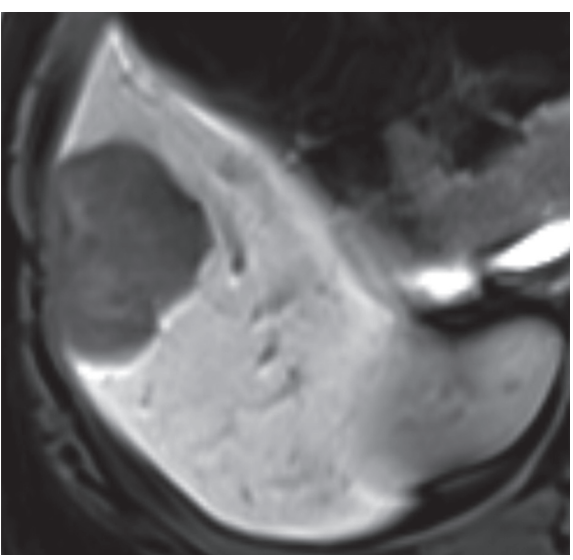

C

Fig. 3. 52-year-old woman with scirrhous HCC and hepatitis B-related cirrhosis.

4.5-cm mass in segment VI of liver shows rim-like enhancement on (A) arterial phase image and peripheral washout with enhancing capsule (arrow) on (B) delayed phase image. Mass shows hypointensity on (C) HBP image and heterogeneous hyperintensity with central dark area (thin arrows) on (D) T2WI. (E) DWI $\left(b=800 \mathrm{sec} / \mathrm{mm}^{2}\right)$ shows targetoid appearance characterized by restricted diffusion in periphery and less restricted diffusion in center.

that the proportion ( $\geq 20 \%$ ) of hyperenhancement on the arterial phase is a helpful feature in distinguishing scirrhous HCCs from ICCs. As mentioned above, not only fibrosis but also central ischemia can induce the targetoid appearance. During hepatocarcinogenesis, arterial flow through unpaired arteries increases in the early stage (well-differentiated HCC to moderately differentiated HCC), but arterial blood supply decreases when moderately differentiated HCCs progress to poorly differentiated HCCs (39). Nakachi et al. (55) also demonstrated that the nonenhancing area within tumors on the arterial phase was more frequently observed in poorly differentiated HCCS than in well- or moderately differentiated HCCs. Moreover, according to Zhao et al. (56), the absence of the washout appearance, tortuous tumor vessels, and presence of bile duct dilatation were more favorable for ICCs than for poorly differentiated HCCS on dynamic CT.
In contrast, among HCC variants, sarcomatous HCCs showed a necrotic tendency since the tumor neovascularization rate could not keep up with the growth rate of sarcomatous components composed of poorly differentiated cells. On CT or MRI, sarcomatous HCCs appear as hypovascular tumors with rim-like enhancement and seldom show the typical APHE and washout (Fig. 4) (40, 41). In a similar vein, large $\mathrm{HCCs}$ ( $\geq 5 \mathrm{~cm}$ ) often show relatively large amount of necrosis and hemorrhage in their internal contents. Consequently, large HCCs could show LR-M (probably or definitely malignant but not HCC specific) features such as peripheral enhancement with centripetal fill-in on CT or MRI $(42,43)$. Hwang et al. (43) demonstrated that capsule, septum, and T2 hyperintense foci were more frequently observed in large HCCs than in ICCs on gadoxetic acid-enhanced MRI. They also commented that biliary dilatation and surface retraction were less 


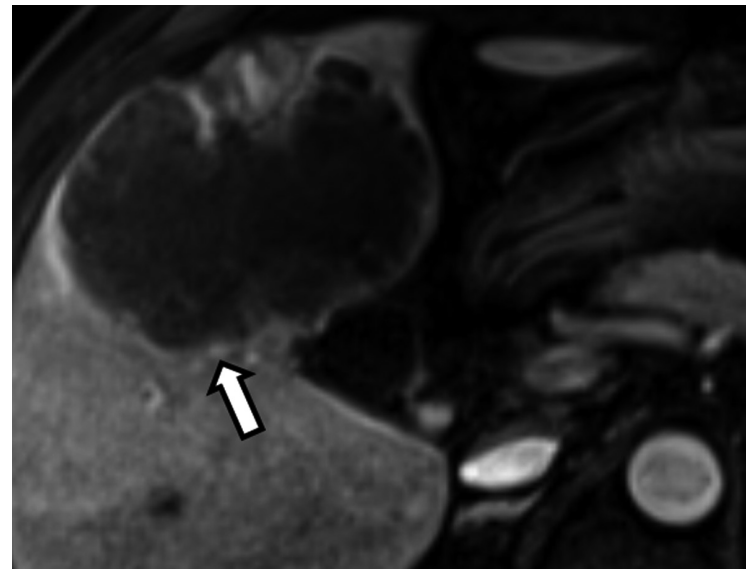

A

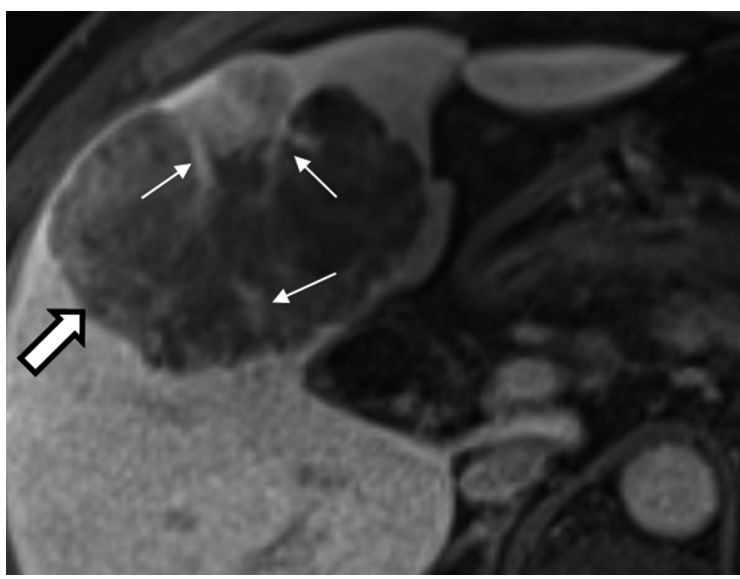

B

Fig. 4. 53-year-old man with sarcomatous HCC and hepatitis B-related cirrhosis.

A. Arterial phase image of gadoxetic acid-enhanced MRI shows hypovascular mass with peripheral rim-like enhancement (arrow). B. Mass shows progressive centripetal enhancement (arrow) and enhancing septae (thin arrows) on transitional phase image.

frequently identified in large HCCs than in ICCs (43).

Finally, according to LI-RADS, tumors with rim enhancement on the arterial phase should be categorized as LR-M. This observation has been confirmed by a recent study, in which approximately $60 \%$ of LR-M observations were proven to be non-HCC malignancies whereas $32 \%$ were $\mathrm{HCCs}$ (37). Therefore, when we encounter HCCs with the targetoid appearance, histological evaluation is warranted for a confirmative diagnosis.

\section{Fibrolamellar HCCs}

Although fibrolamellar HCCs also contain fibrotic components within the tumors, their fibrotic tissue forms a central scar with radiating septa within the tumors and is often accompanied by central calcifications. Since fibrolamellar HCCs mainly occur in young adults (usually in the third decade) without underlying cirrhosis or chronic liver disease $(57,58)$, typical imaging features of HCCs such as cirrhosis, vascular invasion, or multifocal disease are uncommon in fibrolamellar carcinoma (59).

On imaging studies, a fibrolamellar HCC is observed as a large, heterogeneous tumor with a lobulated margin, a central stellate scar in $65-70 \%$ of cases, and calcification in $40-68 \%$ of cases (Fig. 5) $(60,61)$. Therefore, the imaging features of fibrolamellar carcinoma can overlap with those of other scar-producing lesions, including focal nodular hyperplasia (FNH), hepatocellular adenoma (HCA) and carcinoma, hemangioma, metastases, and CC (59). Fibrolamellar HCCs usually show heterogeneous enhancement of the tumor with delayed enhancement of the central scar and radiating septa instead of peripheral rim-like enhancement on dynamic CT and MRI (59). In addition, unlike classical HCCs, APHE and washout are uncommon in fibrolamellar HCCs. Rather, they have central scars with low SI on both T1- and T2WI as well as low SI on the HBP of gadoxetic acid-enhanced MRI, different from FNH (Fig. 5) $(60,62,63)$.

\section{Infiltrative HCCs and Intraductal Growing HCCs}

Infiltrative HCCs, which account for $7 \%$ to $13 \%$ of all HCCs $(64,65)$, usually show a diffuse and permeative appearance and have ill-defined and invasive borders probably due to their invasive nature. Portal vein tumor thrombosis (PVTT) is a characteristic feature of infiltrative $\mathrm{HCCS}$ on imaging studies, with its frequency ranging from $68 \%$ to $100 \%(65,66)$. PVTT can be a primary imaging feature of infiltrative HCCs since the demarcation of the main mass is usually unclear (67). Since PVTT can affect the hemodynamics of the tumor, infiltrative HCCs may not exhibit the typical imaging features of HCCs such as APHE or washout. In this situation, the correct diagnosis of infiltrative HCCs may be difficult. However, several studies have proven that a combined interpretation using the HBP of gadoxetic acid-enhanced MRI and DWI may be helpful in diagnosing infiltrative HCCs (Fig. 6) (67, 68). In addition, although HCC is the most common hepatic tumor associated with tumors in veins, the differential diagnosis should include ICC and, rarely, other malignancies. Since imaging criteria to distinguish HCCs with tumors in veins from other cancers with tumors in veins has not yet been developed, multidisciplinary discussion is recommended to individualize the workup for the management of these patients (7). 


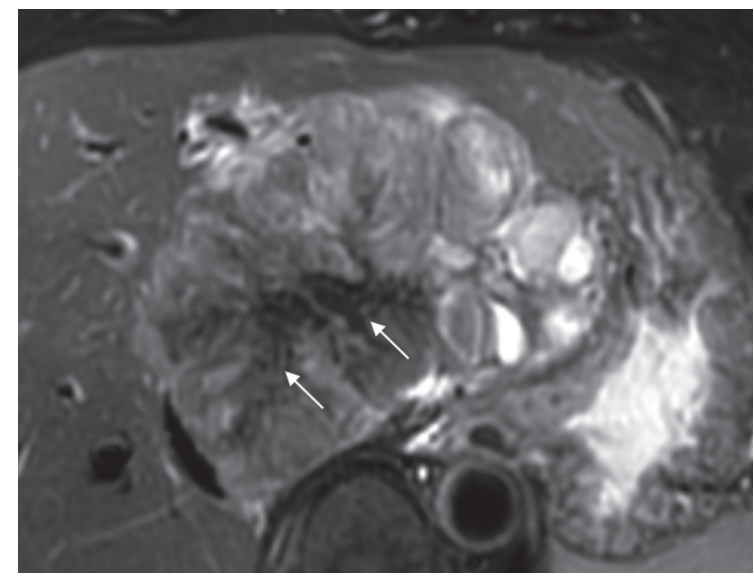

A

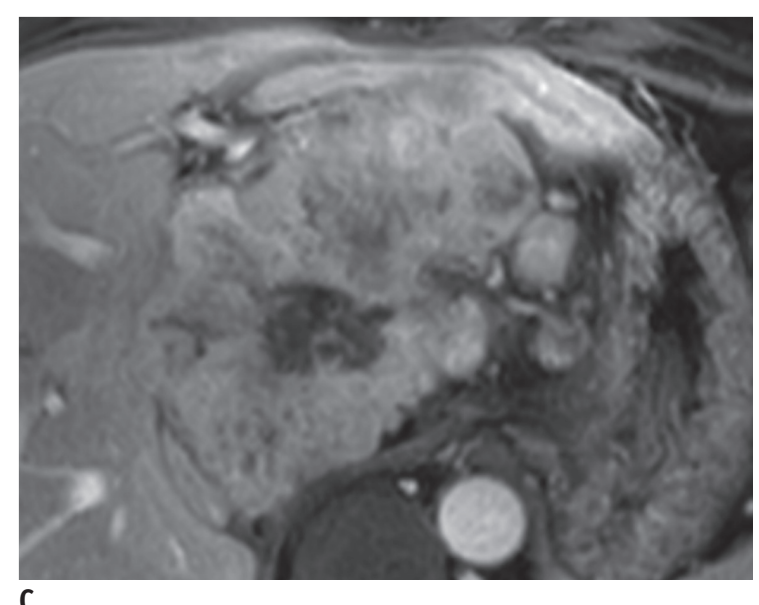

C

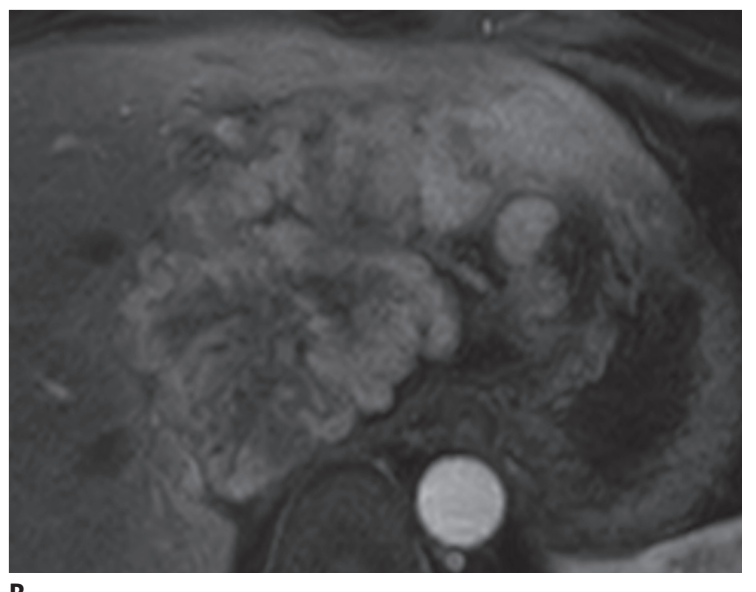

B

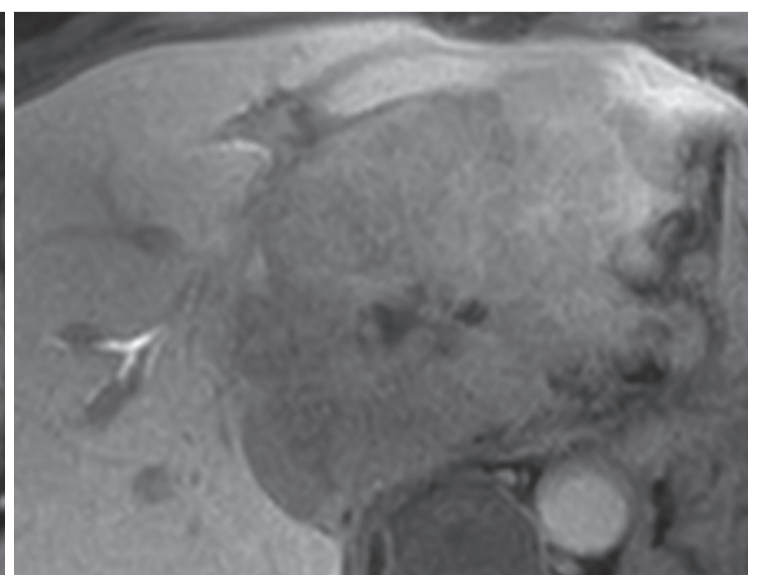

D

Fig. 5. Gadoxetic acid-enhanced magnetic resonance images of fibrolamellar HCC in 34-year-old woman without underlying liver disease.

A. T2WI shows large, heterogeneous mass with hypointense central scar (thin arrows). (B) Arterial and (C) portal venous phase images show progressive enhancement pattern. D. Mass is mostly hypointense on HBP image.

An intraductal growing appearance or bile duct invasion is rarely observed in HCCs, with a reported incidence ranging from only $1.2 \%$ to $9 \%(69,70)$. Patients with intraductal growing HCCs frequently show obstructive jaundice with initial symptoms similar to intraductal CCs. However, the prognosis is quite different between the two disease entities: intraductal CCs usually show a favorable prognosis after complete surgical resection (71) whereas the intraductal growth pattern or bile duct invasion predominantly occurs in the advanced stage of HCCs (69). Therefore, it would be vital to differentiate intraductal growing HCCs from intraductal CCs. According to Jung et al. (72), the presence of a parenchymal mass, liver cirrhosis, and hyperenhancement of intraductal tumor on the arterial phase of dynamic CT can suggest intraductal growing HCCs rather than intraductal CCs (Fig. 7). In addition, laboratory data such as elevated alpha-fetoprotein (AFP) levels may also be useful to correctly diagnose intraductal growing HCCs (73).

\section{Mimickers of HCC on Imaging Studies}

\section{Malignant Lesions}

\section{Intrahepatic Mass-Forming Cholangiocarcinoma}

ICC is a primary hepatic adenocarcinoma that arises from the biliary epithelium (74) and shares several risk factors with $\mathrm{HCC}$ such as chronic viral hepatitis or liver cirrhosis (75). However, since its treatment strategy is quite different from that of $\mathrm{HCC}$, correct differentiation of intrahepatic mass-forming cholangiocarcinoma (IMCC) from HCC on imaging studies is of critical importance. As for imaging characteristics, small IMCCs tend to show homogeneous arterial enhancement on imaging studies owing to the large 

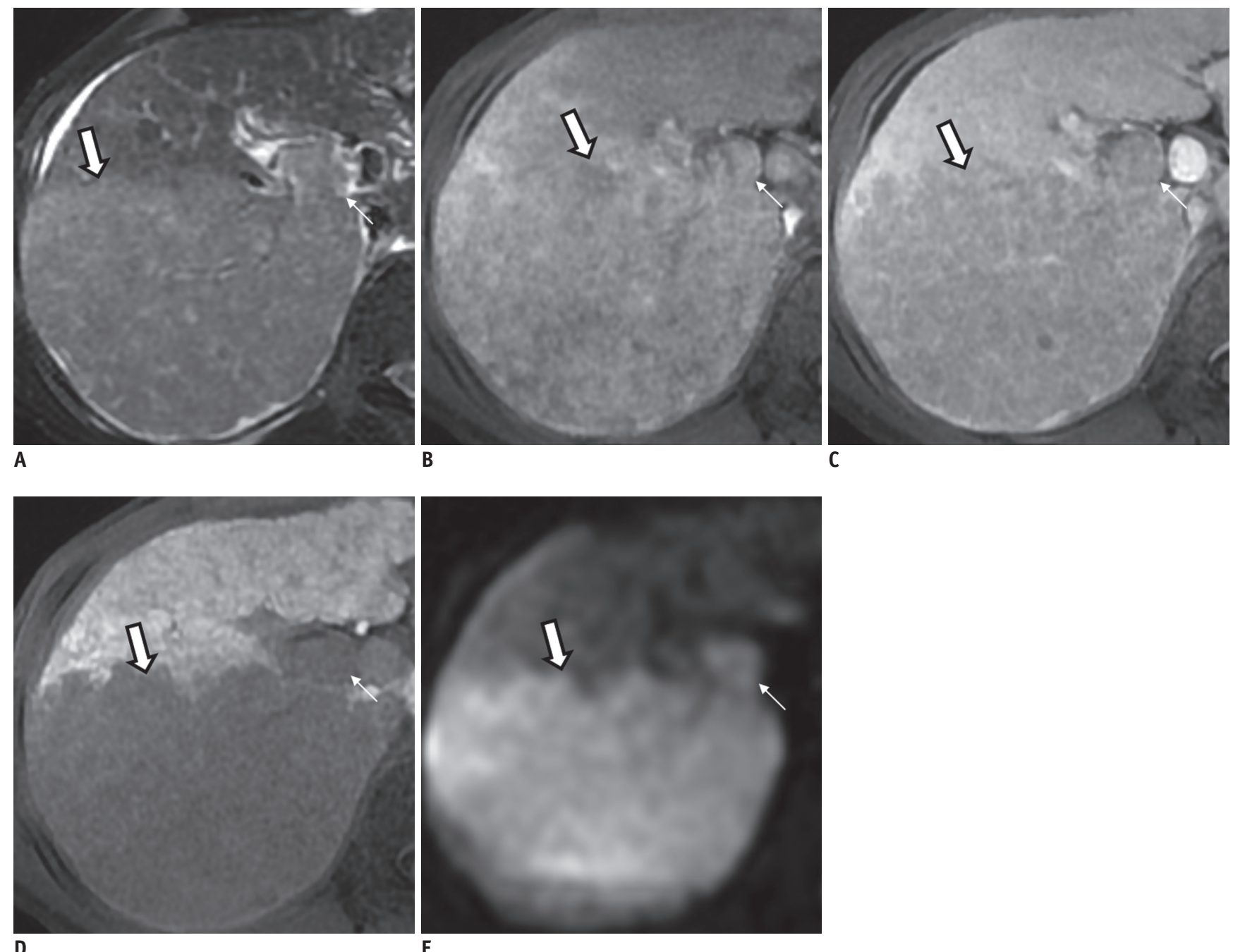

Fig. 6. 55-year-old man with infiltrative HCC and B-related cirrhosis.

A. T2WI shows infiltrative mass (arrow) in right hepatic lobe with portal vein tumor thrombosis (thin arrow). B. Arterial phase image shows mild enhancement in ill-defined mass (arrow) as well as tumor thrombi (thin arrow). C. Mass (arrow) and tumor thrombi (thin arrow) demonstrate subtle washout on portal venous phase image. (D) HBP and (E) DWIs $\left(b=1000 \mathrm{sec} / \mathrm{mm}^{2}\right)$ well depict both mass (arrows) and portal vein tumor thrombosis (thin arrows).

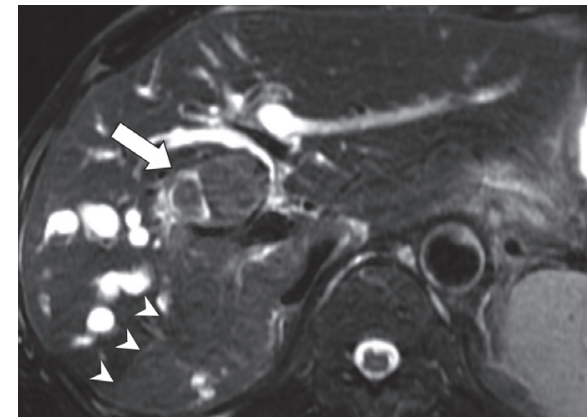

A

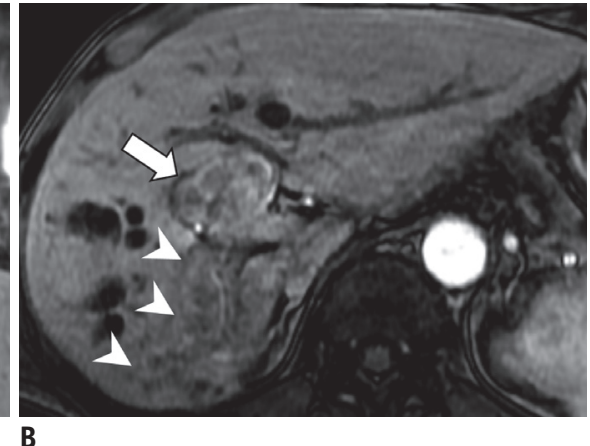

B

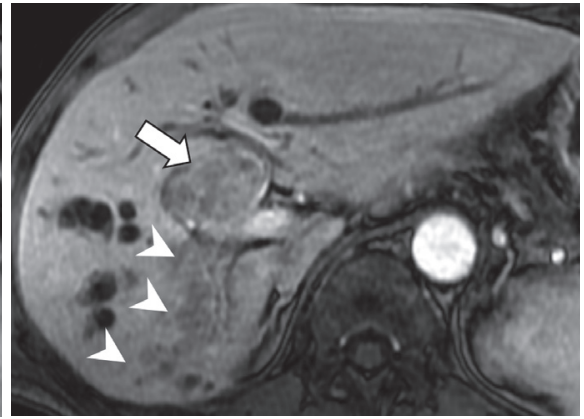

C

Fig. 7. Intraductal growing HCC in 64-year-old man without underlying liver disease.

A. T2WI shows intraductal growing mass (arrow) at proximal bile duct with peripheral intrahepatic bile duct dilatation and ill-defined parenchymal tumor (arrowheads) in right posterior segment of liver. Intraductal lesion (arrows) shows heterogeneous enhancement on (B) arterial phase image and washout on (C) portal venous phase image. Hepatic parenchymal lesion (arrowheads) also shows similar enhancement pattern to intraductal lesion. 

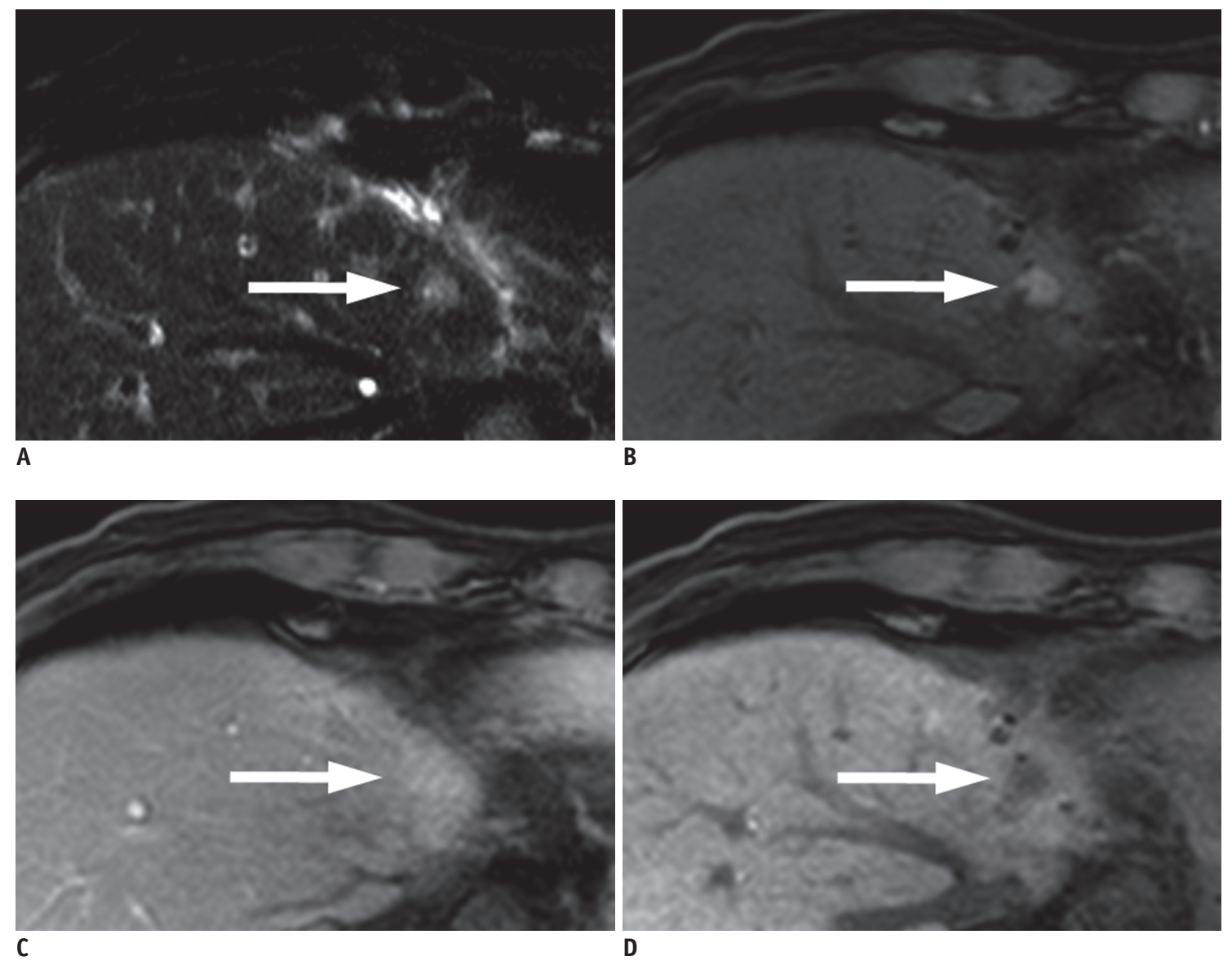

Fig. 8. 59-year-old man with intrahepatic mass-forming cholangiocarcinoma and chronic hepatitis B.

(A) T2WI shows hyperintense nodule (arrow) in left lobe of liver. Nodule (arrows) demonstrates definite enhancement on (B) arterial phase image and isointensity on (C) portal venous phase image. D. HBP image demonstrates hypointensity of lesion (arrow).

number of tumor cells and lack of fibrotic tissue (Fig. 8) (76, 77). This imaging feature could mimic HCCs, especially in patients with liver cirrhosis or chronic liver disease $(77,78)$. When the tumor size increases, fibrotic tissue and necrosis will also increase, and IMCCs may then show peripheral arterial enhancement and a delayed fill-in pattern (Fig. 9) (78-80). According to recent studies, ICCs originate from two topographically and histologically different cholangiocytes: mucin-producing cholangiocytes located in large bile ducts (large duct-type), and non-mucin-producing cholangiocytes with bipotential HPCs located in intrahepatic bile ductules or Canals of Hering (small duct-type) $(81,82)$. On dynamic MRI, large duct-type ICC presents the typical arterial peripheral enhancement and delayed concentric fill-in pattern whereas small duct-type ICC frequently shows diffuse or nodular enhancement on the arterial phase and washout on the delayed phase $(78,81)$.

On extracellular agent-enhanced MRI and CT, IMCCs seldom show delayed washout than HCCs, although substantial proportions of small HCCs and IMCCs still presented similar enhancement patterns $(83,84)$. On gadoxetic acid-enhanced MRI, however, IMCCs could show washout on the transitional phase due to the strong enhancement of background liver (85). Therefore, in order to prevent the misdiagnosis of IMCC as HCC, LI-RADS, EASLEORTC, and AASLD guidelines recommend that the washout appearance should be determined on the portal venous phase if gadoxetic acid is used (86). Although this criterion of portal washout can prevent the misdiagnosis of IMCC as $\mathrm{HCC}$, it inevitably results in significantly lower sensitivity for the diagnosis of HCC $(85,86)$.

Recent studies have demonstrated that the targetoid appearance on dynamic or HBP imaging as well as on DWI may also be useful for the differentiation of IMCCs from HCCs on gadoxetic acid-enhanced MRI $(85,87)$. Based on these study results, the KLCSG-NCC V2018 guidelines now include "washout" not only in the portal or transitional phase but also hypointensity on the HBP after applying the 


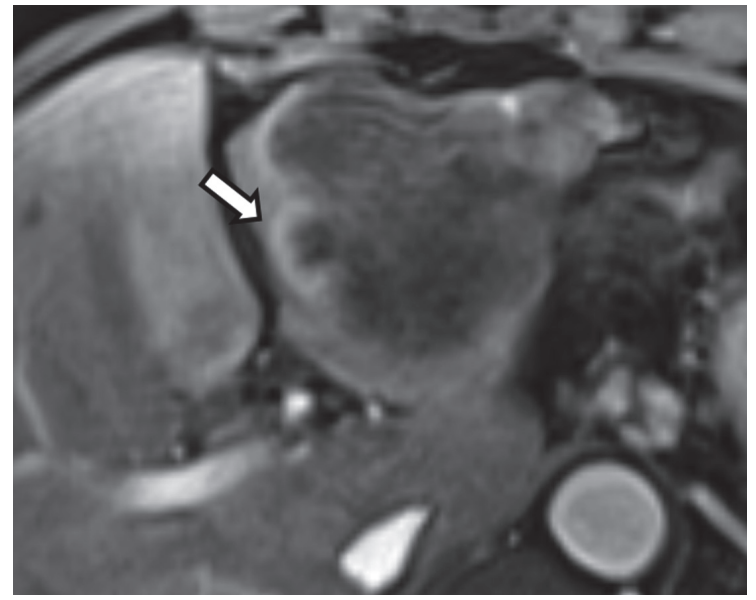

A

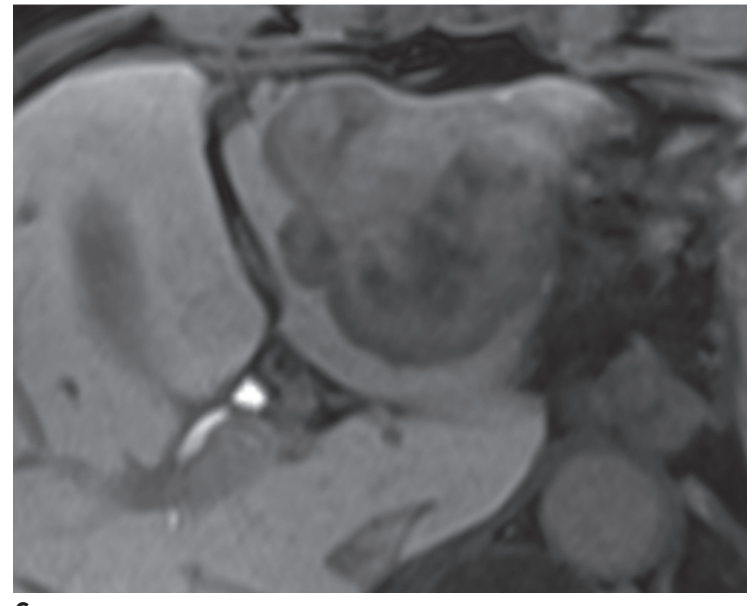

C

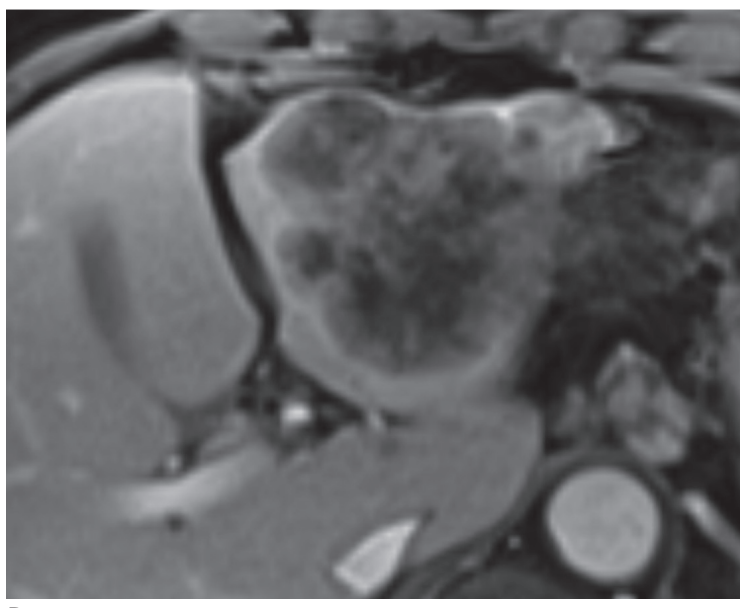

B

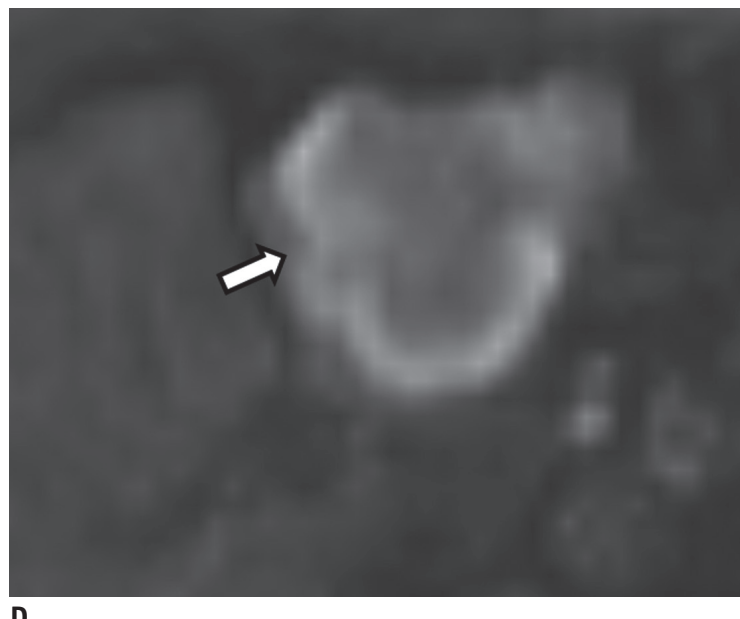

Fig. 9. Intrahepatic mass-forming cholangiocarcinoma in 70-year-old woman without underlying liver disease.

In left hepatic lobe, there is large mass with peripheral enhancement (arrow) on (A) arterial phase image and centripetal enhancement on (B) delayed phase image. C. On HBP image, targetoid appearance characterized by marked hypointensity in periphery with mild hypointensity in center is noted. D. On DWI $\left(b=800 \mathrm{sec} / \mathrm{mm}^{2}\right)$, mass also shows targetoid appearance of central hypointensity with peripheral hyperintensity (arrow).

exclusion criteria of a targetoid appearance on gadoxetic acid-enhanced MRI. Nevertheless, as the targetoid appearance may not be presented with small IMCCS on MRI, additional validation studies should be performed to ascertain the range of specificity that can be achieved with these diagnostic criteria.

\section{Combined Hepatocellular Carcinoma-Cholangiocarcinoma}

CHCC-CC is an uncommon primary liver cancer containing unequivocal, intimately mixed components of both $\mathrm{HCC}$ and $\mathrm{CC}$ with a reported incidence of less than $1 \%$ among all primary liver cancers (88). Patients with CHCC-CCs generally show a worse prognosis than patients with HCCs $(89,90)$ and are usually considered to be contraindicated for liver transplantation (91). Therefore, it would be critical to differentiate $\mathrm{CHCC}-\mathrm{CC}$ from $\mathrm{HCC}$ on preoperative imaging studies.

On imaging, cHCC-CCs typically show a mixture of both $\mathrm{HCC}$ and $\mathrm{CC}$ imaging features as CHCC-CCs contain histological elements of both (47). In general, cHCC-CCs more frequently show enhancement patterns mimicking an ICC rather than a HCC on dynamic CT and MRI (Fig. 10) (9294). According to the study by Fowler et al. (93), cHCC-CCs generally showed intermediate imaging features somewhere between HCCS and CCs on dynamic CT and MRI.

In the differential diagnosis of $\mathrm{CHCC}-\mathrm{CC}$ from $\mathrm{HCC}$, Potretzke et el. (95) suggested that false-positive diagnoses of HCCs can be decreased using ancillary features. In this study, 54\% (33/61) of cHCC-CCs showed the LI-RADS major imaging feature of HCC, which is APHE followed by washout 


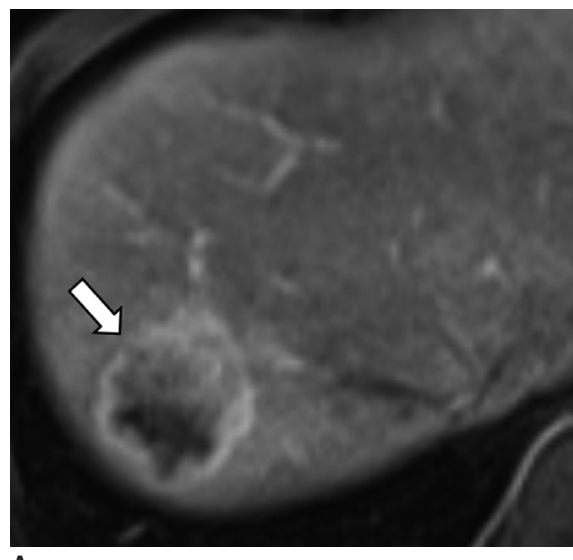

A

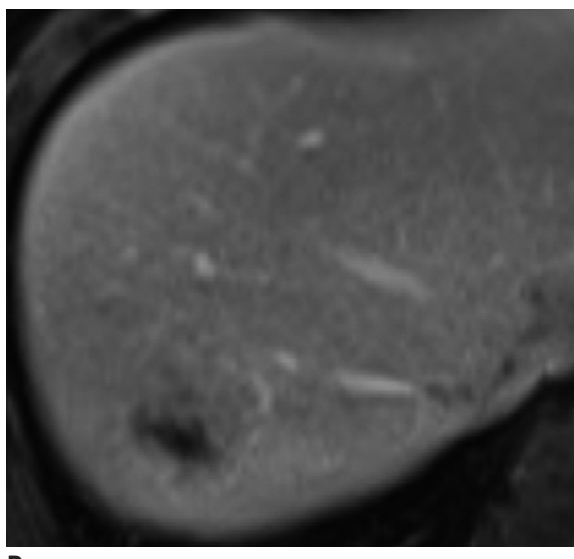

B

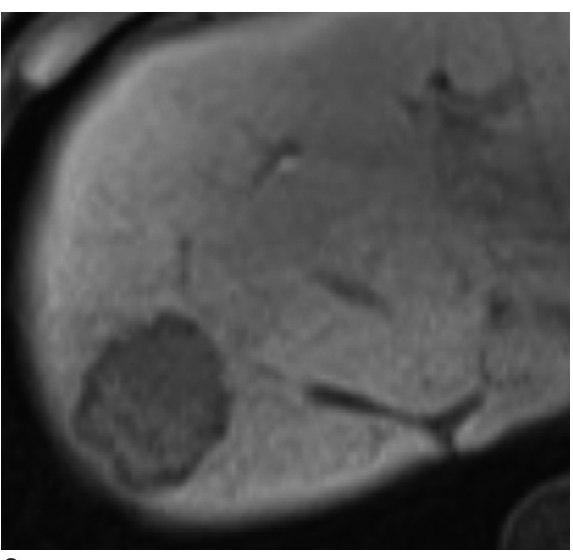

C

Fig. 10. 52-year-old man with cHCC-CC and chronic hepatitis B.

A. Arterial phase image shows mass with peripheral enhancement (arrow) in segment VII of liver. B. Mass shows centripetal enhancement on transitional phase image. C. Note targetoid appearance on HBP image. Although peripheral rim-like hyperenhancement on arterial phase and targetoid appearance on HBP suggest high probability of non-HCC malignancies such as intrahepatic mass-forming cholangiocarcinoma or cHCCCC, normal carbohydrate antigen $19-9$ and elevated alpha-fetoprotein $(289.9 \mathrm{ng} / \mathrm{mL})$ levels suggest high probability of $\mathrm{cHCC}-\mathrm{CC}$ in this patient. CHCC-CC = combined HCC-cholangiocarcinoma

and the capsule appearance. However, ancillary features such as the presence of marked diffusion restriction or the absence of an intralesional fat component allowed correct differentiation of cHCC-CC from HCC $(95,96)$. Nevertheless, $\mathrm{CHCC}-\mathrm{CC}$ is a heterogeneous disease entity that can be difficult to differentiate from HCC based on imaging studies alone. Recently, Jeon et al. (97) demonstrated that a substantial proportion of $\mathrm{CHCC}-\mathrm{CC}$ could be categorized as LR-5 (definitely HCC) or LR-4 (probably HCC) on gadoxetic acid-enhanced MRI. Therefore, combined interpretation of imaging findings and tumor markers such as AFP and carbohydrate antigen (CA) 19-9 may be useful to diagnose cHCC-CC preoperatively (Fig. 10) $(47,98,99)$. For example, the diagnosis of $\mathrm{CHCC}-\mathrm{CC}$ can be considered in the following situations: 1) imaging features favoring $\mathrm{HCC}$ with elevated CA 19-9 levels; 2) mixed imaging features of HCC and CC with elevated AFP and CA 19-9 levels; or 3) imaging features favoring $\mathrm{CC}$ with elevated AFP levels.

\section{Benign Lesions}

\section{Hemangioma}

Typical imaging features of hemangiomas are peripheral globular or nodular enhancement similar to the enhancement of blood vessels, followed by centripetal fill-in enhancement on the portal venous phase (100). However, differentiating small fast-filling hemangiomas from small HCCs remains a diagnostic challenge. This is because small fast-filling hemangiomas tend to show lower attenuation than the portal vein in the portal venous phase $(101,102)$, while small HCCs often show atypical enhancement patterns such as the absence of washout on the portal phase (103). Furthermore, fast-filling hemangiomas frequently show the "pseudo-washout" sign on the transitional phase of gadoxetic acid-enhanced MRI due to the uptake of hepatobiliary agents by the adjacent normal liver (Fig. 11) $(102,104)$. Indeed, pseudo-washout is a well-known cause of false-positive diagnoses of HCCs when washout on the transitional phase or low SI on the HBP are used as part of the diagnostic criteria (86). Therefore, according to the Japan Society of Hepatology guidelines, fast-filling hemangiomas should first be ruled out using another modality when radiologists encounter masses without washout (105). In addition, KLCSG-NCC v2018 guidelines also recommend that hemangioma should be ruled out using bright SI on T2WI and heavily T2WI (Fig. 11). Moreover, hemangiomas show high apparent diffusion coefficient values on DWI in contrast to HCCs, which typically show diffusion restriction (106).

\section{Hepatocellular Adenoma}

Histologically, HCAs are composed of benign hepatocytes arranged in cord- or plate-like fashion with the plates separated by dilated sinusoids (107), and these sinusoids and feeding arteries can cause hypervascular imaging features. Poor connective tissue support is also associated with the hemorrhagic tendency of this tumor. Although HCA usually occurs in young women with a history of oral 


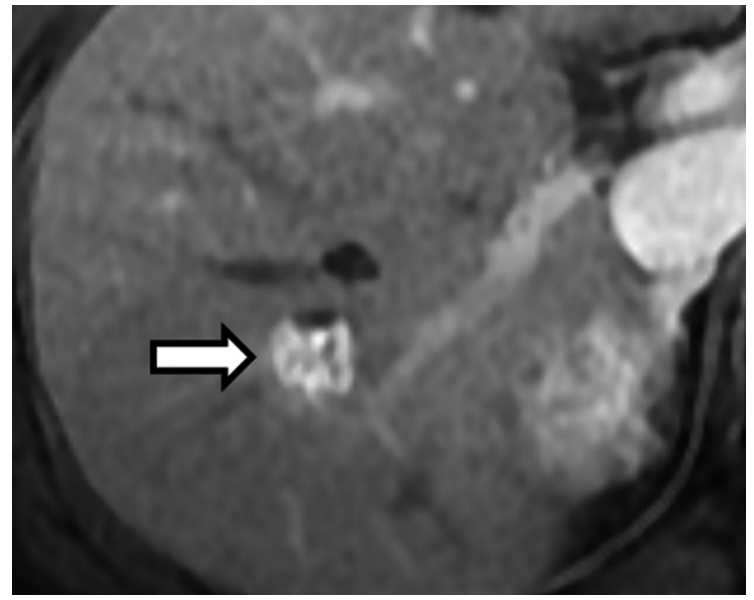

A

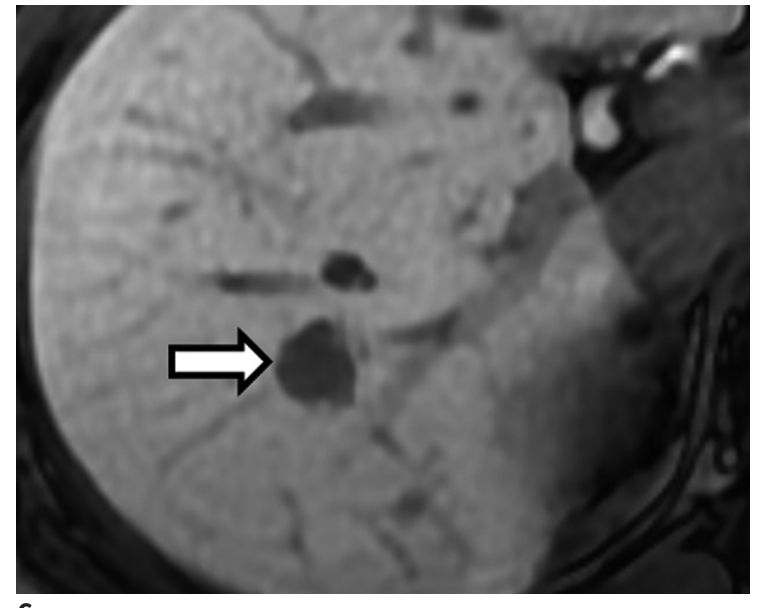

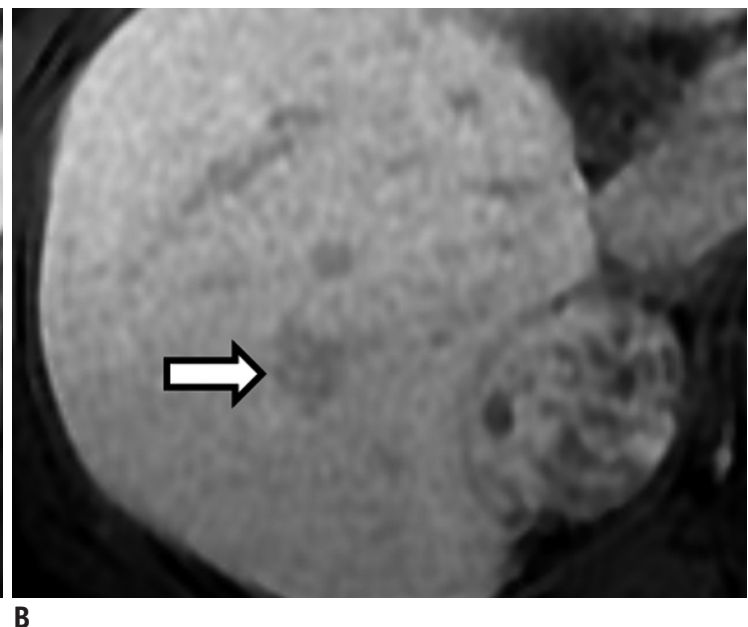

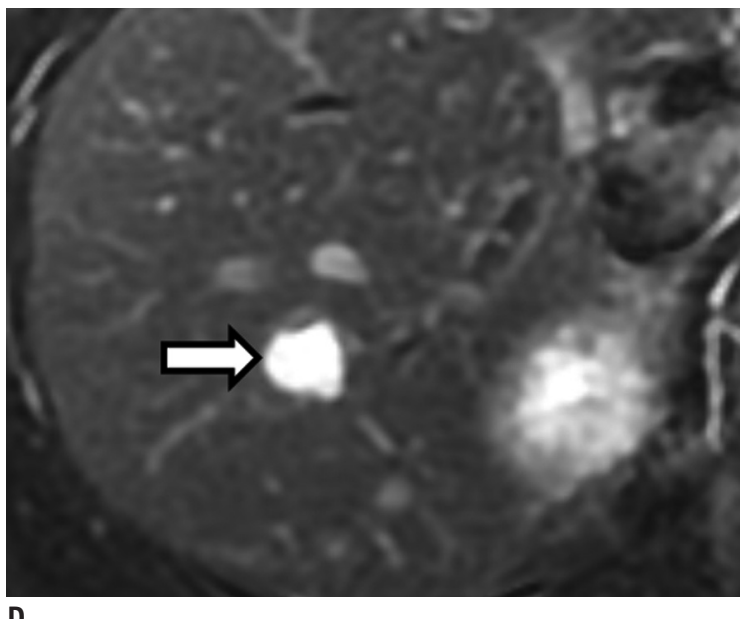

Fig. 11. 48-year-old woman with hemangioma and chronic hepatitis B.

A. Nodule (arrow) shows prominent enhancement on arterial phase image. Note relative hypointensity of nodule (arrows) due to gadoxetic acid uptake by adjacent liver parenchyma on (B) transitional phase image ("pseudo-washout" sign) and dark signal intensity on (C) HBP image. D. T2WI depicts bright signal intensity of lesion (arrow).

contraceptive use, it may still be difficult to differentiate HCAs from HCCs when they occur in the non-cirrhotic liver. According to recent studies (108-110), HCAs can be categorized into four subtypes based on their genetic and pathologic features: inflammatory HCAs, hepatocyte nuclear factor (HNF)- $1 \alpha$-mutated HCAs, $\beta$-catenin-mutated HCAs, and unclassified HCAs that have no genetic abnormalities. Imaging features on MRI can play a key role in the diagnosis and subtype characterization of HCAs. Inflammatory HCAs frequently show low SI on T1WI, the absence of a signal drop on chemical shift images, diffuse high SI on T2WI, and a persistent enhancement pattern on MRI (Fig. 12) (111, 112). Inflammatory HCAs could also show variable uptake in the HBP because several factors including sinusoidal dilatation, inflammatory component, and ductal reaction can result in low SI on the HBP, mainly at the periphery
(113). On the other hand, Glockner et al. (114) recently reported that a considerable portion of inflammatory HCAs $(33 \%, 9 / 27)$ showed peripheral hyperenhancement and central hypoenhancement on the HBP. These features also create the "atoll sign" on T2WI, which reflects its peripheral high SI (115). Persistent enhancement on dynamic imaging could be a key imaging feature to differentiate inflammatory HCAs from HCCs. However, according to Tse et al. (116), inflammatory HCAs did not show persistent enhancement on the transitional phase of gadoxetic acid-enhanced MRI, probably due to background liver enhancement (Fig. 12). HNF-1 $\alpha$-mutated HCAs show hyper- or iso-SI on T1WI, a diffuse signal drop on chemical shift images, iso- or slightly hyper-SI on T2WI, weak APHE, hypo-SI on portal venous and delayed phases, and homogeneous hypo-SI on the HBP $(111,112)$. The diffuse signal drop on chemical shift 


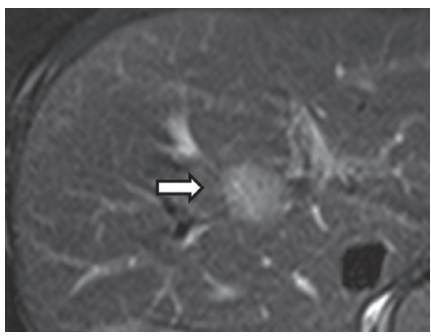

A

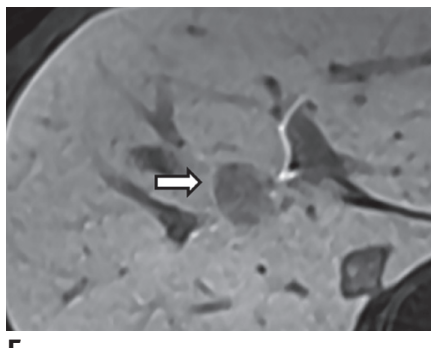

E

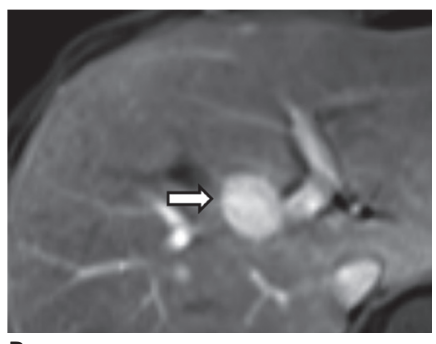

B

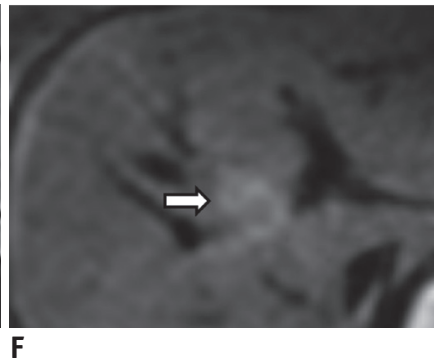

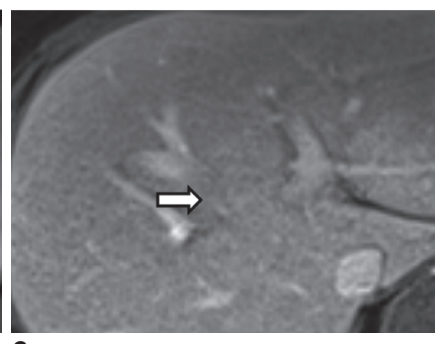

C

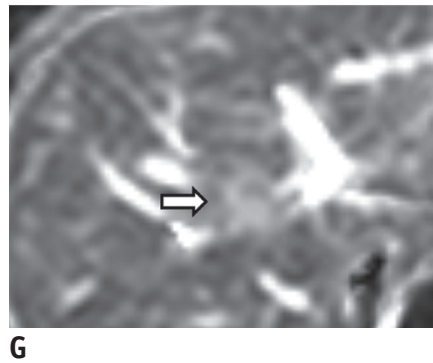

Fig. 12. Inflammatory HCA in 36-year-old woman without underlying liver disease.

A. T2WI shows hyperintense nodule (arrow) in segment VIII of liver. Lesion (arrows) shows prominent enhancement on (B) arterial phase image and iso-signal intensity on (C) portal venous phase image. D. Note relatively low signal intensity of lesion (arrow) on transitional phase image. $\mathbf{E}$. Nodule (arrow) shows low signal intensity on HBP image. On (F) DWI $\left(b=800 \mathrm{sec} / \mathrm{mm}^{2}\right)$ and (G) apparent diffusion coefficient map, lesion (arrows) shows high signal intensity indicating no restricted diffusion. $\mathrm{HCA}=$ hepatocellular adenoma

images is more suggestive for HNF-1-mutated HCAs than HCCs (115). $\beta$-catenin-mutated HCA usually shows variable imaging features such as homogeneous or heterogeneous hypervascularity with a persistent or non-persistent enhancement and variable SI on T1- and T2WI (Fig. 13) (111). Finally, at present, no characteristic imaging features of unclassified HCA have been demonstrated.

On gadoxetic acid-enhanced MRI, most HCAs show arterial enhancement and low SI on the transitional phase as mentioned above (111-113). Furthermore, according to a recent meta-analysis performed by Guo et al. (117), a pooled proportion of low SI on the HBP for HCAs was $89 \%$. However, the capsule appearance on portal or delayed phases has been reported to be more common in HCCs than in HCAs $(42-81 \%$ versus $31 \%$ ) (Figs. 12,13$)(83,118-$ $120)$. Since the mosaic architecture is unusual in tumors other than HCCs (22), it could also be a useful imaging feature for differentiation between HCCs and HCAs (Figs. 12, 13). Furthermore, although HCAs could show restricted diffusion on DWI, the absence of diffusion restriction suggests a benign rather than a malignant lesion (Fig. 12) $(106,121)$. Nevertheless, it would still be difficult to distinguish early HCCs from HCAs in the cirrhotic liver unless the lesion shows capsule formation and a mosaic architecture.

\section{Focal Nodular Hyperplasia}

Hepatic FNH is a benign nodular lesion without malignant potential that frequently occurs in middle-aged women without liver cirrhosis. It is composed of benign-appearing hepatocytes separated by radiating fibrous cords originating from a central scar (122). A typical FNH presents as an area of homogeneous arterial hyperenhancement with central scar enhancement on the later phases of dynamic CT or MRI (Fig. 14). FNH typically shows iso- or hypo-SI on T1WI, slightly hyper- or iso-SI on T2WI, and a hyperSI central scar on T2WI (Fig. 14) (122). On gadoxetic acidenhanced MRI, although the large central scar could present with low SI on the HBP (123), most FNHs show iso- or hyper- SI on the HBP owing to the presence of functioning hepatocytes (Fig. 14) (124). In addition, FNH sometimes shows ring- or doughnut-like enhancement on the HBP due to hyperplastic hepatocytes in the central portion with decreased OATP expression (125). Although most HCCs show low SI on the HBP, approximately $5-12 \%$ of HCCs consisting of moderately differentiated tumor cells with OATP overexpression also show hyperenhancement on the HBP (22). Thus, it is necessary for radiologists to differentiate FNHs from HCCs with hyperenhancement on HBP images. In order to correctly differentiate these HCCs from FNHs, ancillary features such as focal defects in contrast uptake, a hypointense rim on the HBP, and absence of a central scar 

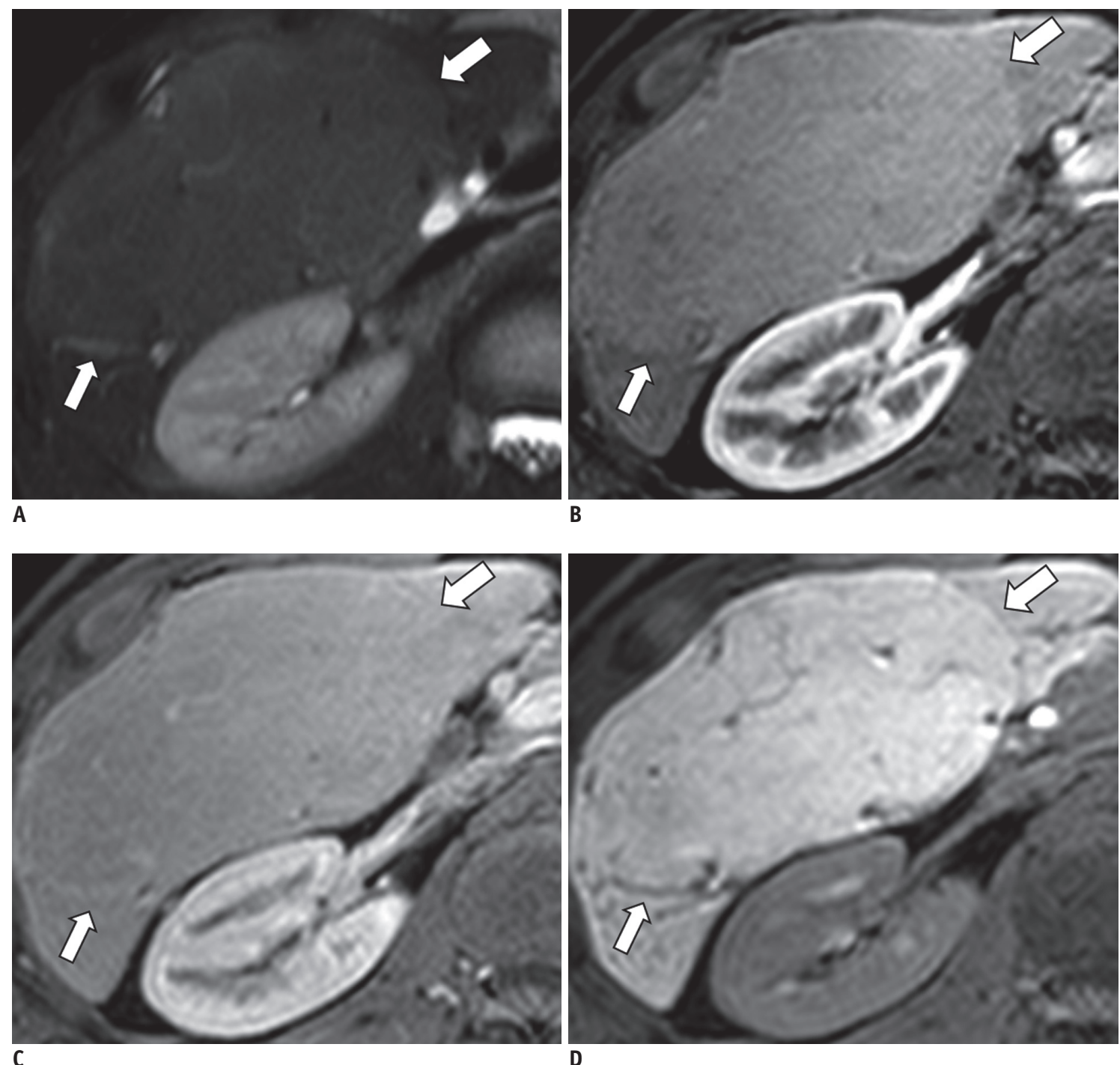

Fig. 13. $\beta$-catenin-mutated HCA in 44-year-old man without underlying liver disease.

A. T2WI demonstrates large mass (arrows) with intermediate signal intensity in liver. Mass (arrows) shows subtle enhancement on (B) arterial phase image and iso-signal intensity on (C) portal venous phase image. D. Note iso-signal intensity of mass (arrows) on HBP image.

or radiating septa may be useful $(22,126)$. Despite these attempts, radiologists can easily misdiagnose a FNH as a LR-4 lesion when FNHs show APHE on MRI (127), especially in patients with chronic liver disease or liver cirrhosis.

Finally, FNH-like nodules can be commonly seen in the cirrhotic liver and are associated with conditions showing abnormal hepatic perfusion such as Budd-Chiari syndrome (128) or congenital heart disease (129). As this lesion is pathologically and immunohistochemically identical to classical FNH in the non-cirrhotic liver, imaging findings of FNH-like nodules would also be the same as those of FNH.

\section{Angiomyolipoma}

Hepatic angiomyolipoma (AML) is a benign mesenchymal tumor that consists of blood vessels, smooth muscle cells, and a varying amount of fat (less than $10 \%$ to more than $90 \%$ ) (130). It usually occurs in patients without liver cirrhosis. Although the presence of fat is a key imaging feature of AML, other hepatic lesions including HCC can also contain fat component. Since the imaging findings of AML and HCC are frequently very similar and $10-12 \%$ of HCCs occur in patients without liver cirrhosis $(131,132)$, a distinction between these two entities would be quite difficult on preoperative imaging studies. For example, AMLS frequently show the washout appearance on portal phase as well as low SI on the HBP of gadoxetic acid-enhanced MRI (Fig. 15). Lee et al. (133) demonstrated that an early draining vein and iso-SI on DWI were more frequently 


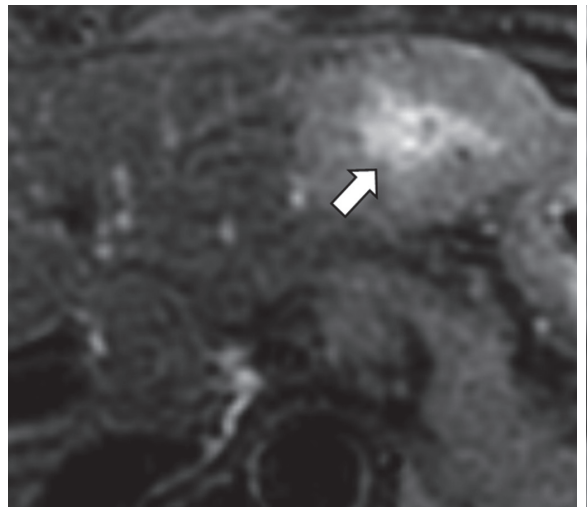

A

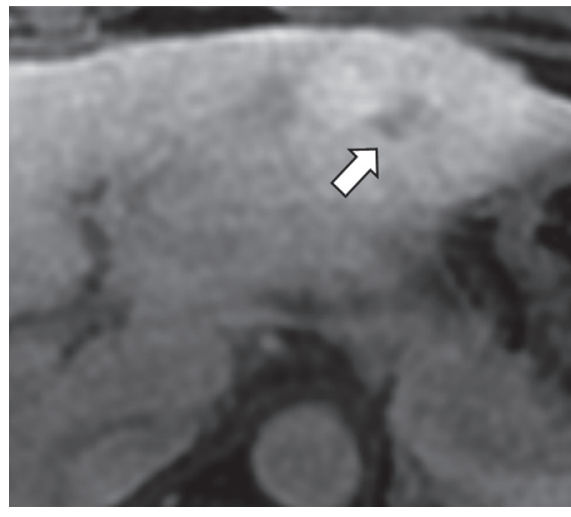

D

Fig. 14. Focal nodular hyperplasia in 45-year-old woman without underlying liver disease.

A. T2WI shows slightly hyperintense mass with hyperintense central scar (arrow) in left lobe of liver. B. Mass shows isointensity with hypointense central scar (arrow) on precontrast T1WI. C. Arterial phase image shows prominent enhancement of mass with nonenhancing central scar (arrow). D. Central scar (arrow) shows delayed enhancement on transitional phase image. E. HBP image demonstrates isointense mass with hypointense central scar (arrow).

observed in AMLs than in HCCs (Fig. 15). Furthermore, Kim et al. (134) proved that AML showed more homogeneous low SI on the HBP than HCCs and that the tumor-to-spleen SI of AML on the HBP was lower than that of HCCs (Fig. 15).

\section{Focal Eosinophilic Liver Disease}

Focal eosinophilic liver disease, including focal eosinophilic infiltration and focal eosinophilic abscess, is an inflammatory hepatic lesion associated with various medical conditions such as parasite infections, allergic reactions, drug hypersensitivity, hypereosinophilic syndrome, and malignancies (135). This lesion usually shows a small illdefined margin with low attenuation or SI on the portal venous phase of dynamic CT or MRI (136). Although focal eosinophilic infiltration frequently shows arterial enhancement, low SI on portal venous, transitional, and HBPs, and high SI on T2WI, it predominantly presents with iso-SI on T1WI and heterogeneous low SI with an ill-defined fuzzy margin on the HBP of gadoxetic acid-enhanced MRI
$(135,137,138)$. Therefore, these characteristic imaging findings and peripheral eosinophilia can help radiologists correctly differentiate focal eosinophilic liver disease from hepatic malignancies such as HCC.

\section{Hypervascular Pseudolesion}

AP shunts are frequently observed as hypervascular pseudolesions in the cirrhotic liver. Communication routes for AP shunts are diverse and include the transsinusoidal, transvasal, peribiliary, and transtumoral routes (139). In particular, hypervascular tumors such as HCC and hemangioma can cause AP shunts through the transtumoral route. However, AP shunts associated with tumors are known to be more common in hemangiomas than in HCCs (140). On dynamic CT or MRI, the typical imaging findings of AP shunts include wedge-shaped homogeneous hypervascular lesions on the arterial phase, early enhancement of peripheral portal vein branches, isoattenuation or iso-SI to the liver with the absence of washout on portal and delayed 

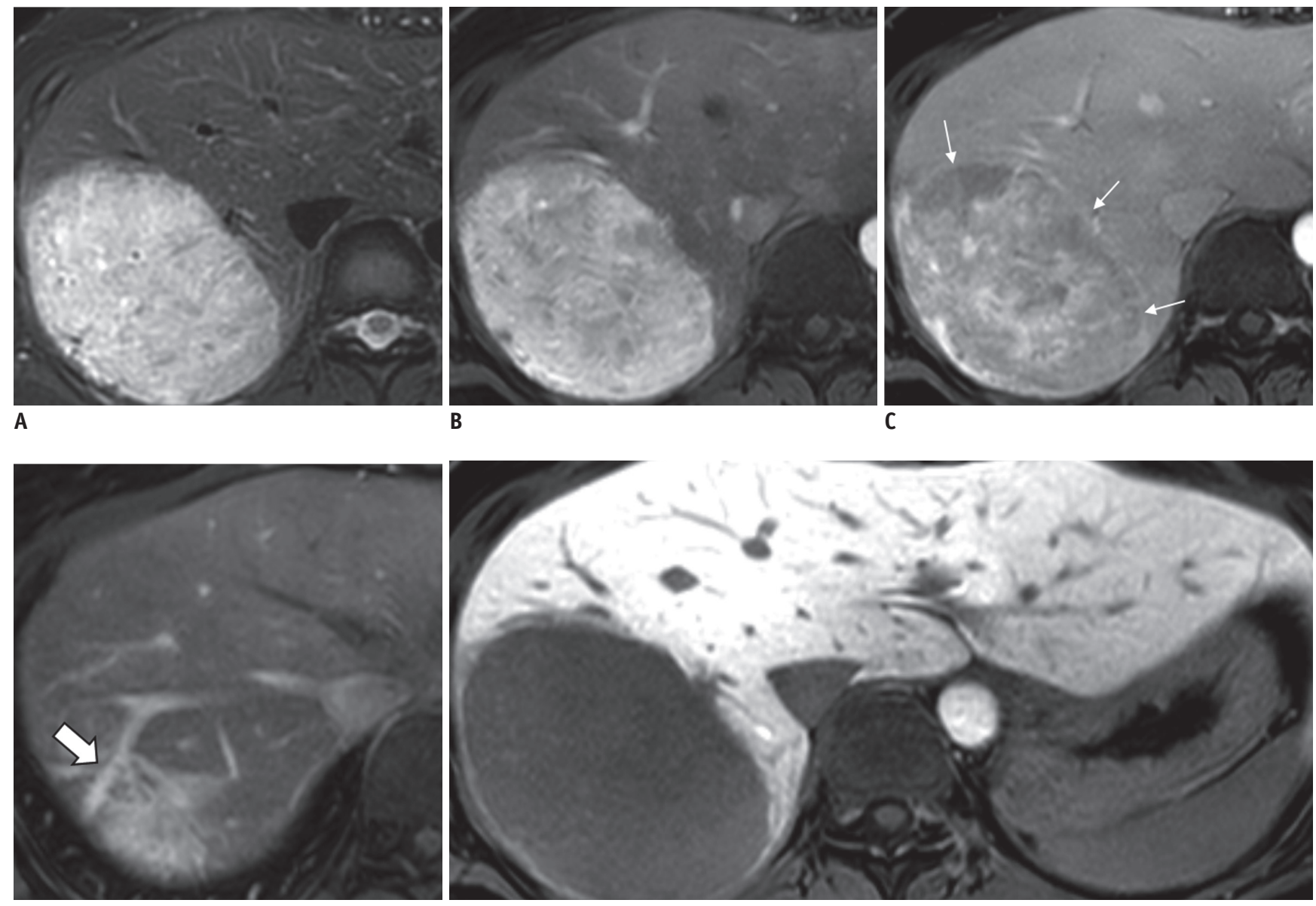

D

E

Fig. 15. Hepatic angiomyolipoma in 39-year-old woman without underlying liver disease.

A. T2WI shows hyperintense mass in right lobe of liver. Mass shows hyperenhancement on (B) arterial phase image and heterogeneous signal intensity with washout portions (thin arrows) on (C) portal venous phase image. D. Early draining vein (arrow) connecting to right hepatic vein is noted on arterial phase image. E. HBP image shows mass with homogeneous hypointensity, which is lower than signal intensity of spleen (tumor-to-spleen signal intensity ratio: 0.96 ).

phases, and subcapsular or peripheral location $(139,141)$. When imaging findings of AP shunts are not typical or small HCCs exhibit an atypical enhancement pattern, features on the HBP of gadoxetic acid-enhanced MRI or DWI may be helpful. AP shunts usually show iso-SI on the HBP and no diffusion restriction on DWI, whereas HCCs usually show low SI on the HBP and diffusion restriction on DWI $(142,143)$.

\section{How to Deal with Challenging Cases}

Current practice guidelines of most major academic societies, including EASL-EORTC, APASL, AASLD, and KLCSGNCC, allow for the noninvasive diagnosis of HCC for atrisk patients without biopsy when imaging tests exhibit the hallmark features of HCC. This is based on the high pre-test probability of HCC in high-risk patients and the high specificity and positive predictive value of these hallmark features on CT and MRI. However, according to these diagnostic guidelines, a definitive diagnosis of HCC cannot be made in tumors with atypical imaging features. Therefore, biopsy would be required for a confirmative diagnosis. In clinical practice, however, although lesions $\geq$ $1 \mathrm{~cm}$ have a substantial likelihood of being malignant (31, 144), it is not always possible to perform percutaneous biopsy for indeterminate nodules in the cirrhotic liver, especially when they are located at unfavorable sites or barely visible on US or unenhanced CT. Moreover, biopsy may cause complications such as bleeding or track seeding and has the potential to yield false-negative results (145). According to the most recent AASLD guideline, biopsy is suggested only in select cases in which a diagnosis can affect the therapeutic decision-making (7). Instead of biopsy for indeterminate nodules, the AASLD guideline suggests several other options such as follow-up imaging 
or imaging with an alternative modality or contrast agent. Therefore, the importance of a multidisciplinary team approach should be stressed for hepatic nodules, particularly for LR-4 and LR-M lesions $\geq 1 \mathrm{~cm}$, so as to develop a more patient-tailored management strategy (7).

Although most guidelines have only focused on distinguishing HCCs from non-HCC lesions, LI-RADS v2018 uses a non-binary decision algorithm covering the whole spectrum of lesions seen in the liver. With LIRADS, hepatic lesions can be classified according to their relative probability of being benign or an HCC (LR-1 to LR5), or another hepatic malignant neoplasm (i.e., LR-M) on the basis of CT, MRI, or contrast-enhanced US findings. Furthermore, it also incorporates ancillary imaging features that can modulate the likelihood of malignancy versus benign tumors and of HCC versus non-HCC malignancies. Ancillary features favoring $\mathrm{HCC}$ include a nonenhancing "capsule," nodule-in-nodule architecture, mosaic architecture, and intralesional fat or blood products while a feature favoring non-HCC malignancy is the targetoid appearance (2). In addition, ancillary features favoring a malignancy, not HCC, include restricted diffusion on DWI, mild-to-moderate high SI on T2WI, and low SI on HBP. These ancillary features allow us to use the multiparametric capability of MRI for the diagnosis of HCC, thereby resulting in an improved diagnostic performance. By virtue of these merits of multiparametric MRI, LI-RADS can resolve issues regarding atypically enhancing HCCs and differentiate HCC mimickers from HCCs in clinical practice. Using the nonbinary LI-RADS classification system, radiologists can categorize the likelihood of HCCs and more confidently diagnose HCCs using the above-mentioned ancillary imaging features, although a definite diagnosis of HCC cannot be made without the major HCC features (146). For example, in cases of non-hypervascular early HCCs, ancillary features such as high SI on T2WI, diffusion restriction, and low SI on HBP can be used to upgrade LR-3 (intermediate probability of malignancy) to LR-4 which would be helpful in achieving a correct diagnosis (147). In addition, if a tumor exhibits the targetoid appearance, which is a suggestive feature for LR-M assignment, radiologists should include an atypical HCC as well as a non-HCC malignancy in their differential diagnosis. However, problems still remain with LI-RADS in the application of ancillary features favoring malignancy, not HCC in particular. For example, although HBP hypoenhancement and restricted diffusion are highly prevalent in malignancies and are strong indicators of malignancy (148), there is no clear distinction in the prevalence and importance of each feature in HCC and nonHCC malignancies in LI-RADS (16). Therefore, hierarchical weighting of each ancillary feature would prove beneficial (16).

Furthermore, as a large HCC seldom shows the hallmark features of HCC such as APHE and washout, but rather presents imaging findings favoring LR-M criteria, including rim APHE and delayed central enhancement, atypical large HCCs can be frequently categorized as LR-M instead of LR-4 or LR-5. Therefore, the differential diagnosis of LR-M should include large $\mathrm{HCC}$ with atypical imaging features as well as IMCC and CHCC-CC in the context of high HCC prevalence (16, 37). Further refinements of the diagnostic criteria in the major guidelines, including LI-RADS, are still warranted to better discriminate non-HCC malignancies from HCCs.

\section{CONCLUSION}

When clinicians or radiologists encounter challenging cases in the cirrhotic liver, a careful interpretation should be performed using multiparametric imaging, including T2WI, HBP, and DWI, in addition to the relative enhancement pattern seen on dynamic CT or MRI. In addition, the application of ancillary features following the LI-RADS diagnostic algorithm would be helpful in making a correct diagnosis in HCCs with atypical features while decreasing false-positive diagnoses. Finally, if the imaging features and laboratory findings still remain insufficient to determine the proper treatment strategy, it would be important to have a multidisciplinary team discussion for these liver lesions so as to develop a more patient-tailored approach for these difficult cases.

\section{Conflicts of Interest}

The authors have no potential conflicts of interest to disclose.

\author{
ORCID iDs \\ Jeong Min Lee \\ https://orcid.org/0000-0003-0561-8777 \\ Jae Hyun Kim \\ https://orcid.org/0000-0002-6691-3932 \\ Ijin Joo \\ https://orcid.org/0000-0002-1341-4072
}




\section{REFERENCES}

1. Mittal S, El-Serag HB. Epidemiology of hepatocellular carcinoma: consider the population. J Clin Gastroenterol 2013;47 Suppl:S2-S6

2. Elsayes KM, Hooker JC, Agrons MM, Kielar AZ, Tang A, Fowler $\mathrm{KJ}$, et al. 2017 version of LI-RADS for CT and MR imaging: an update. Radiographics 2017;37:1994-2017

3. Forner A, Reig M, Bruix J. Hepatocellular carcinoma. Lancet 2018;391:1301-1314

4. European Association for Study of Liver; European Organisation for Research and Treatment of Cancer. EASL-EORTC clinical practice guidelines: management of hepatocellular carcinoma. Eur J Cancer 2012;48:599-641

5. Bruix J, Sherman M; American Association for the Study of Liver Diseases. Management of hepatocellular carcinoma: an update. Hepatology 2011;53:1020-1022

6. European Association for the Study of the Liver. Electronic address: easloffice@easloffice.eu; European Association for the Study of the Liver. EASL clinical practice guidelines: management of hepatocellular carcinoma. $J$ Hepatol 2018;69:182-236

7. Marrero JA, Kulik LM, Sirlin CB, Zhu AX, Finn RS, Abecassis $M M$, et al. Diagnosis, staging, and management of hepatocellular carcinoma: 2018 practice guidance by the American Association for the Study of Liver Diseases. Hepatology 2018;68:723-750

8. Omata M, Cheng AL, Kokudo N, Kudo M, Lee JM, Jia J, et al. Asia-Pacific clinical practice guidelines on the management of hepatocellular carcinoma: a 2017 update. Hepatol Int 2017;11:317-370

9. Yoon JH, Park JW, Lee JM. Noninvasive diagnosis of hepatocellular carcinoma: elaboration on Korean Liver Cancer Study Group-National Cancer Center Korea practice guidelines compared with other guidelines and remaining issues. Korean J Radiol 2016;17:7-24

10. Forner A, Vilana R, Ayuso C, Bianchi L, Solé M, Ayuso $J R$, et al. Diagnosis of hepatic nodules $20 \mathrm{~mm}$ or smaller in cirrhosis: prospective validation of the noninvasive diagnostic criteria for hepatocellular carcinoma. Hepatology 2008;47:97-104

11. Cruite I, Tang A, Sirlin CB. Imaging-based diagnostic systems for hepatocellular carcinoma. AJR Am J Roentgenol 2013;201:41-55

12. Lee JH, Lee JM, Kim SJ, Baek JH, Yun SH, Kim KW, et al. Enhancement patterns of hepatocellular carcinomas on multiphasicmultidetector row CT: comparison with pathological differentiation. Br J Radiol 2012;85:e573-e583

13. Choi JY, Lee JM, Sirlin CB. CT and MR imaging diagnosis and staging of hepatocellular carcinoma: part I. Development, growth, and spread: key pathologic and imaging aspects. Radiology 2014;272:635-654

14. Fournier LS, Cuenod CA, de Bazelaire C, Siauve N, Rosty C, Tran PL, et al. Early modifications of hepatic perfusion measured by functional CT in a rat model of hepatocellular carcinoma using a blood pool contrast agent. Eur Radiol 2004; 14:2125-2133

15. Kitao A, Zen Y, Matsui 0, Gabata T, Nakanuma Y. Hepatocarcinogenesis: multistep changes of drainage vessels at CT during arterial portography and hepatic arteriography-radiologic-pathologic correlation. Radiology 2009;252:605614

16. Kim YY, Choi JY, Sirlin CB, An C, Kim MJ. Pitfalls and problems to be solved in the diagnostic CT/MRI Liver Imaging Reporting and Data System (LI-RADS). Eur Radiol 2019;29:1124-1132

17. International Consensus Group for Hepatocellular Neoplasia. Pathologic diagnosis of early hepatocellular carcinoma: a report of the International Consensus Group for Hepatocellular Neoplasia. Hepatology 2009;49:658-664

18. Kojiro M. Histopathology of liver cancers. Best Pract Res Clin Gastroenterol 2005;19:39-62

19. Tang A, Bashir MR, Corwin MT, Cruite I, Dietrich CF, Do RKG, et al.; LI-RADS Evidence Working Group. Evidence supporting LI-RADS major features for CT- and MR imaging-based diagnosis of hepatocellular carcinoma: a systematic review. Radiology 2018;286:29-48

20. Kojiro M. 'Nodule-in-nodule' appearance in hepatocellular carcinoma: its significance as a morphologic marker of dedifferentiation. Intervirology 2004;47:179-183

21. Liver Imaging Reporting and Data System. American College of Radiology Web site. https://www.acr.org/ClinicalResources/Reporting-and-Data-Systems/LI-RADS/CT-MRILI-RADS-v2018. Published July, 2018. Accessed October 1, 2018

22. Choi JY, Lee JM, Sirlin CB. CT and MR imaging diagnosis and staging of hepatocellular carcinoma: part II. Extracellular agents, hepatobiliary agents, and ancillary imaging features. Radiology 2014;273:30-50

23. Shah S, Shukla A, Paunipagar B. Radiological features of hepatocellular carcinoma. J Clin Exp Hepatol 2014;4(Suppl 3):S63-S66

24. Kim JH, Lee JM, Yoon JH, Lee DH, Lee KB, Han JK, et al. Portal vein thrombosis in patients with hepatocellular carcinoma: diagnostic accuracy of gadoxetic acid-enhanced MR imaging. Radiology 2016;279:773-783

25. Bartolozzi C, Battaglia V, Bozzi E. HCC diagnosis with liverspecific MRI--close to histopathology. Dig Dis 2009;27:125130

26. Sano K, Ichikawa T, Motosugi U, Sou H, Muhi AM, Matsuda $M$, et al. Imaging study of early hepatocellular carcinoma: usefulness of gadoxetic acid-enhanced MR imaging. Radiology 2011;261:834-844

27. Kitao A, Matsui 0, Yoneda N, Kozaka K, Shinmura R, Koda $W$, et al. The uptake transporter OATP8 expression decreases during multistep hepatocarcinogenesis: correlation with gadoxetic acid enhanced MR imaging. Eur Radiol 2011;21:2056-2066 
28. Kim BR, Lee JM, Lee DH, Yoon JH, Hur BY, Suh KS, et al. Diagnostic performance of gadoxetic acid-enhanced liver MR imaging versus multidetector CT in the detection of dysplastic nodules and early hepatocellular carcinoma. Radiology 2017;285:134-146

29. Tang A, Cruite I, Mitchell DG, Sirlin CB. Hepatocellular carcinoma imaging systems: why they exist, how they have evolved, and how they differ. Abdom Radiol (NY) 2018;43:312

30. Wald C, Russo MW, Heimbach JK, Hussain HK, Pomfret EA, Bruix J. New OPTN/UNOS policy for liver transplant allocation: standardization of liver imaging, diagnosis, classification, and reporting of hepatocellular carcinoma. Radiology 2013;266:376-382

31. Yoon JH, Lee JM, Yang HK, Lee KB, Jang JJ, Han JK, et al. Non-hypervascular hypointense nodules $\geq 1 \mathrm{~cm}$ on the hepatobiliary phase of gadoxetic acid-enhanced magnetic resonance imaging in cirrhotic livers. Dig Dis 2014;32:678689

32. Theise ND, Curado MP, Franceschi S, Hytiroglou P, Kudo M, Park YN, et al. Hepatocellular carcinoma. In: Bosman FT, Carneiro, F, Hruban RH, Theise ND, eds. WHO classification of tumours of the digestive system, 4th ed. Lyon: IARC, 2010:205-216

33. Takayama T, Makuuchi M, Hirohashi S, Sakamoto M, Yamamoto J, Shimada K, et al. Early hepatocellular carcinoma as an entity with a high rate of surgical cure. Hepatology 1998;28:1241-1246

34. Farinati F, Sergio A, Baldan A, Giacomin A, Di Nolfo MA, Del Poggio $P$, et al. Early and very early hepatocellular carcinoma: when and how much do staging and choice of treatment really matter? A multi-center study. BMC Cancer 2009;9:33

35. Rhee H, Kim MJ, Park MS, Kim KA. Differentiation of early hepatocellular carcinoma from benign hepatocellular nodules on gadoxetic acid-enhanced MRI. Br J Radiol 2012; 85:e837-e844

36. Kim YK, Lee WJ, Park MJ, Kim SH, Rhim H, Choi D. Hypovascular hypointense nodules on hepatobiliary phase gadoxetic acid-enhanced MR images in patients with cirrhosis: potential of DW imaging in predicting progression to hypervascular HCC. Radiology 2012;265:104-114

37. Fraum TJ, Tsai R, Rohe E, Ludwig DR, Salter A, Nalbantoglu $I$, et al. Differentiation of hepatocellular carcinoma from other hepatic malignancies in patients at risk: diagnostic performance of the Liver Imaging Reporting and Data System version 2014. Radiology 2018;286:158-172

38. Shafizadeh N, Kakar S. Hepatocellular carcinoma: histologic subtypes. Surg Pathol Clin 2013;6:367-384

39. Asayama Y, Yoshimitsu K, Nishihara Y, Irie H, Aishima S, Taketomi A, et al. Arterial blood supply of hepatocellular carcinoma and histologic grading: radiologic-pathologic correlation. AJR Am J Roentgenol 2008;190:W28-W34

40. Gu KW, Kim YK, Min JH, Ha SY, Jeong WK. Imaging features of hepatic sarcomatous carcinoma on computed tomography and gadoxetic acid-enhanced magnetic resonance imaging. Abdom Radiol (NY) 2017;42:1424-1433

41. Honda H, Hayashi T, Yoshida K, Takenaka K, Kaneko K, Fukuya $T$, et al. Hepatocellular carcinoma with sarcomatous change: characteristic findings of two-phased incremental CT. Abdom Imaging 1996;21:37-40

42. Blaschke EM, Rao VL, Xiong L, Te HS, Hart J, Reddy KG, et al. Multiphase multi-detector row computed tomography imaging characteristics of large $(>5 \mathrm{~cm})$ focal hepatocellular carcinoma. J Comput Assist Tomogr 2016;40:493-497

43. Hwang J, Kim YK, Min JH, Choi SY, Jeong WK, Hong SS, et al. Capsule, septum, and T2 hyperintense foci for differentiation between large hepatocellular carcinoma $(\geq 5$ $\mathrm{cm}$ ) and intrahepatic cholangiocarcinoma on gadoxetic acid MRI. Eur Radiol 2017;27:4581-4590

44. Kim H, Choi GH, Na DC, Ahn EY, Kim GI, Lee JE, et al. Human hepatocellular carcinomas with "Stemness"-related marker expression: keratin 19 expression and a poor prognosis. Hepatology 2011;54:1707-1717

45. Seok JY, Na DC, Woo HG, Roncalli M, Kwon SM, Yoo JE, et al. A fibrous stromal component in hepatocellular carcinoma reveals a cholangiocarcinoma-like gene expression trait and epithelial-mesenchymal transition. Hepatology 2012;55:1776-1786

46. Fujii T, Zen Y, Harada K, Niwa H, Masuda S, Kaizaki Y, et al. Participation of liver cancer stem/progenitor cells in tumorigenesis of scirrhous hepatocellular carcinoma--human and cell culture study. Hum Pathol 2008;39:1185-1196

47. Joo I, Kim H, Lee JM. Cancer stem cells in primary liver cancers: pathological concepts and imaging findings. Korean J Radiol 2015;16:50-68

48. Brunt E, Aishima S, Clavien PA, Fowler K, Goodman Z, Gores $\mathrm{G}$, et al. cHCC-CCA: consensus terminology for primary liver carcinomas with both hepatocytic and cholangiocytic differentation. Hepatology 2018;68:113-126

49. Sia D, Villanueva A, Friedman SL, Llovet JM. Liver cancer cell of origin, molecular class, and effects on patient prognosis. Gastroenterology 2017;152:745-761

50. Jeong HT, Kim MJ, Kim YE, Park YN, Choi GH, Choi JS. MRI features of hepatocellular carcinoma expressing progenitor cell markers. Liver Int 2012;32:430-440

51. Kurogi M, Nakashima 0, Miyaaki H, Fujimoto M, Kojiro M. Clinicopathological study of scirrhous hepatocellular carcinoma. J Gastroenterol Hepatol 2006;21:1470-1477

52. Kim SH, Lim HK, Lee WJ, Choi D, Park CK. Scirrhous hepatocellular carcinoma: comparison with usual hepatocellular carcinoma based on CT-pathologic features and long-term results after curative resection. Eur J Radiol 2009;69:123-130

53. Park MJ, Kim YK, Park HJ, Hwang J, Lee WJ. Scirrhous hepatocellular carcinoma on gadoxetic acid-enhanced magnetic resonance imaging and diffusion-weighted imaging: emphasis on the differentiation of intrahepatic 
cholangiocarcinoma. J Comput Assist Tomogr 2013;37:872881

54. Choi SY, Kim YK, Min JH, Kang TW, Jeong WK, Ahn S, et al. Added value of ancillary imaging features for differentiating scirrhous hepatocellular carcinoma from intrahepatic cholangiocarcinoma on gadoxetic acid-enhanced MR imaging. Eur Radiol 2018;28:2549-2560

55. Nakachi K, Tamai H, Mori Y, Shingaki N, Moribata K, Deguchi $\mathrm{H}$, et al. Prediction of poorly differentiated hepatocellular carcinoma using contrast computed tomography. Cancer Imaging 2014;14:7

56. Zhao YJ, Chen WX, Wu DS, Zhang WY, Zheng LR. Differentiation of mass-forming intrahepatic cholangiocarcinoma from poorly differentiated hepatocellular carcinoma: based on the multivariate analysis of contrastenhanced computed tomography findings. Abdom Radiol (NY) 2016;41:978-989

57. El-Serag HB, Davila JA. Is fibrolamellar carcinoma different from hepatocellular carcinoma? A US population-based study. Hepatology 2004;39:798-803

58. Craig JR, Peters RL, Edmondson HA, Omata M. Fibrolamellar carcinoma of the liver: a tumor of adolescents and young adults with distinctive clinico-pathologic features. Cancer 1980;46:372-379

59. McLarney JK, Rucker PT, Bender GN, Goodman ZD, Kashitani N, Ros PR. Fibrolamellar carcinoma of the liver: radiologicpathologic correlation. Radiographics 1999;19:453-471

60. Ichikawa T, Federle MP, Grazioli L, Madariaga J, Nalesnik M, Marsh W. Fibrolamellar hepatocellular carcinoma: imaging and pathologic findings in 31 recent cases. Radiology 1999;213:352-361

61. Friedman AC, Lichtenstein JE, Goodman Z, Fishman EK, Siegelman SS, Dachman AH. Fibrolamellar hepatocellular carcinoma. Radiology 1985;157:583-587

62. Ringe KI, Husarik DB, Sirlin CB, Merkle EM. Gadoxetate disodium-enhanced MRI of the liver: part 1, protocol optimization and lesion appearance in the noncirrhotic liver. AJR Am J Roentgenol 2010;195:13-28

63. Seale MK, Catalano OA, Saini S, Hahn PF, Sahani DV. Hepatobiliary-specific MR contrast agents: role in imaging the liver and biliary tree. Radiographics 2009;29:1725-1748

64. Trevisani F, Caraceni P, Bernardi M, D'Intino PE, Arienti V, Amorati $\mathrm{P}$, et al. Gross pathologic types of hepatocellular carcinoma in Italian patients. Relationship with demographic, environmental, and clinical factors. Cancer 1993;72:1557-1563

65. Kanematsu M, Semelka RC, Leonardou P, Mastropasqua M, Lee JK. Hepatocellular carcinoma of diffuse type: MR imaging findings and clinical manifestations. J Magn Reson Imaging 2003;18:189-195

66. Kneuertz PJ, Demirjian A, Firoozmand A, Corona-Villalobos C, Bhagat N, Herman J, et al. Diffuse infiltrative hepatocellular carcinoma: assessment of presentation, treatment, and outcomes. Ann Surg Oncol 2012;19:2897-2907
67. Lim S, Kim YK, Park HJ, Lee WJ, Choi D, Park MJ. Infiltrative hepatocellular carcinoma on gadoxetic acid-enhanced and diffusion-weighted MRI at 3.0T. J Magn Reson Imaging 2014;39:1238-1245

68. Park YS, Lee $\mathrm{CH}$, Kim BH, Lee J, Choi JW, Kim KA, et al. Using Gd-EOB-DTPA-enhanced 3-T MRI for the differentiation of infiltrative hepatocellular carcinoma and focal confluent fibrosis in liver cirrhosis. Magn Reson Imaging 2013;31:11371142

69. Kojiro M, Kawabata K, Kawano Y, Shirai F, Takemoto N, Nakashima T. Hepatocellular carcinoma presenting as intrabile duct tumor growth: a clinicopathologic study of 24 cases. Cancer 1982;49:2144-2147

70. Leong JW, Ho JM, Ng HS, Raj JP. Early hepatocellular carcinoma presenting with biliary ductal invasion--a case report. Ann Acad Med Singapore 2000;29:101-104

71. Suh KS, Roh HR, Koh YT, Lee KU, Park YH, Kim SW. Clinicopathologic features of the intraductal growth type of peripheral cholangiocarcinoma. Hepatology 2000;31:12-17

72. Jung AY, Lee JM, Choi SH, Kim SH, Lee JY, Kim SW, et al. Computed tomography features of an intraductal polypoid mass: differentiation between hepatocellular carcinoma with bile duct tumor invasion and intraductal papillary cholangiocarcinoma. J Comput Assist Tomogr 2006;30:18-24

73. Kim AY, Jeong WK. Intraductal malignant tumors in the liver mimicking cholangiocarcinoma: imaging features for differential diagnosis. Clin Mol Hepatol 2016;22:192-197

74. Joo I, Lee JM, Yoon JH. Imaging diagnosis of intrahepatic and perihilar cholangiocarcinoma: recent advances and challenges. Radiology 2018;288:7-13

75. Shaib YH, El-Serag HB, Nooka AK, Thomas M, Brown TD, Patt $Y Z$, et al. Risk factors for intrahepatic and extrahepatic cholangiocarcinoma: a hospital-based case-control study. Am J Gastroenterol 2007;102:1016-1021

76. Yoshida Y, Imai Y, Murakami T, Nishikawa M, Kurokawa M, Yonezawa $T$, et al. Intrahepatic cholangiocarcinoma with marked hypervascularity. Abdom Imaging 1999;24:66-68

77. Kim SA, Lee JM, Lee KB, Kim SH, Yoon SH, Han JK, et al. Intrahepatic mass-forming cholangiocarcinomas: enhancement patterns at multiphasic CT, with special emphasis on arterial enhancement pattern--correlation with clinicopathologic findings. Radiology 2011;260:148-157

78. Kang Y, Lee JM, Kim SH, Han JK, Choi BI. Intrahepatic mass-forming cholangiocarcinoma: enhancement patterns on gadoxetic acid-enhanced MR images. Radiology 2012;264:751-760

79. Valls C, Gumà A, Puig I, Sanchez A, Andía E, Serrano T, et al. Intrahepatic peripheral cholangiocarcinoma: CT evaluation. Abdom Imaging 2000;25:490-496

80. Iavarone M, Piscaglia F, Vavassori S, Galassi M, Sangiovanni $A$, Venerandi $L$, et al. Contrast enhanced CT-scan to diagnose intrahepatic cholangiocarcinoma in patients with cirrhosis. $J$ Hepatol 2013;58:1188-1193

81. Komuta M, Govaere 0, Vandecaveye V, Akiba J, Van 
Steenbergen W, Verslype C, et al. Histological diversity in cholangiocellular carcinoma reflects the different cholangiocyte phenotypes. Hepatology 2012;55:1876-1888

82. Cardinale V, Semeraro R, Torrice A, Gatto M, Napoli C, Bragazzi MC, et al. Intra-hepatic and extra-hepatic cholangiocarcinoma: new insight into epidemiology and risk factors. World J Gastrointest Oncol 2010;2:407-416

83. Rimola J, Forner A, Tremosini S, Reig M, Vilana R, Bianchi $\mathrm{L}$, et al. Non-invasive diagnosis of hepatocellular carcinoma $\leq 2 \mathrm{~cm}$ in cirrhosis. Diagnostic accuracy assessing fat, capsule and signal intensity at dynamic MRI. J Hepatol 2012;56:1317-1323

84. Huang B, Wu L, Lu XY, Xu F, Liu CF, Shen WF, et al. Small intrahepatic cholangiocarcinoma and hepatocellular carcinoma in cirrhotic livers may share similar enhancement patterns at multiphase dynamic MR imaging. Radiology 2016;281:150-157

85. Kim R, Lee JM, Shin CI, Lee ES, Yoon JH, Joo I, et al. Differentiation of intrahepatic mass-forming cholangiocarcinoma from hepatocellular carcinoma on gadoxetic acid-enhanced liver MR imaging. Eur Radiol 2016;26:1808-1817

86. Joo I, Lee JM, Lee DH, Jeon JH, Han JK, Choi BI. Noninvasive diagnosis of hepatocellular carcinoma on gadoxetic acid-enhanced MRI: can hypointensity on the hepatobiliary phase be used as an alternative to washout? Eur Radiol 2015;25:2859-2868

87. Park HJ, Kim YK, Park MJ, Lee WJ. Small intrahepatic massforming cholangiocarcinoma: target sign on diffusionweighted imaging for differentiation from hepatocellular carcinoma. Abdom Imaging 2013;38:793-801

88. Theise N, Nakashima 0, Park YN, Nakanuma Y. Combined hepatocellular-cholangiocarcinoma. In: Bosman FT, Carneiro F, Hruban RH, Theise ND, eds. WHO classification of tumours of the digestive system, 4th ed. Lyon: IARC, 2010:225-227

89. Lee WS, Lee KW, Heo JS, Kim SJ, Choi SH, Kim YI, et al. Comparison of combined hepatocellular and cholangiocarcinoma with hepatocellular carcinoma and intrahepatic cholangiocarcinoma. Surg Today 2006;36:892897

90. Yano Y, Yamamoto J, Kosuge T, Sakamoto Y, Yamasaki S, Shimada K, et al. Combined hepatocellular and cholangiocarcinoma: a clinicopathologic study of 26 resected cases. Jpn J Clin Oncol 2003;33:283-287

91. Gupta R, Togashi J, Akamatsu N, Sakamoto Y, Kokudo N. Impact of incidental/misdiagnosed intrahepatic cholangiocarcinoma and combined hepatocellular cholangiocarcinoma on the outcomes of liver transplantation: an institutional case series and literature review. Surg Today 2017;47:908-917

92. Fukukura Y, Taguchi J, Nakashima 0, Wada Y, Kojiro M. Combined hepatocellular and cholangiocarcinoma: correlation between CT findings and clinicopathological features. $J$ Comput Assist Tomogr 1997;21:52-58
93. Fowler KJ, Sheybani A, Parker RA 3rd, Doherty S, M Brunt E, Chapman WC, et al. Combined hepatocellular and cholangiocarcinoma (biphenotypic) tumors: imaging features and diagnostic accuracy of contrast-enhanced CT and MRI. AJR Am J Roentgenol 2013;201:332-339

94. Hwang J, Kim YK, Park MJ, Lee MH, Kim SH, Lee WJ, et al. Differentiating combined hepatocellular and cholangiocarcinoma from mass-forming intrahepatic cholangiocarcinoma using gadoxetic acid-enhanced MRI. J Magn Reson Imaging 2012;36:881-889

95. Potretzke TA, Tan BR, Doyle MB, Brunt EM, Heiken JP, Fowler $\mathrm{KJ}$. Imaging features of biphenotypic primary liver carcinoma (hepatocholangiocarcinoma) and the potential to mimic hepatocellular carcinoma: LI-RADS analysis of CT and MRI features in 61 cases. AJR Am J Roentgenol 2016;207:25-31

96. Horvat N, Nikolovski I, Long N, Gerst S, Zheng J, Pak LM, et al. Imaging features of hepatocellular carcinoma compared to intrahepatic cholangiocarcinoma and combined tumor on MRI using liver imaging and data system (LI-RADS) version 2014. Abdom Radiol (NY) 2018;43:169-178

97. Jeon SK, Joo I, Lee DH, Lee SM, Kang HJ, Lee KB, et al. Combined hepatocellular cholangiocarcinoma: LI-RADS v2017 categorisation for differential diagnosis and prognostication on gadoxetic acid-enhanced MR imaging. Eur Radiol 2019;29:373-382

98. Li R, Yang D, Tang CL, Cai P, Ma KS, Ding SY, et al. Combined hepatocellular carcinoma and cholangiocarcinoma (biphenotypic) tumors: clinical characteristics, imaging features of contrast-enhanced ultrasound and computed tomography. BMC Cancer 2016;16:158

99. Tang D, Nagano H, Nakamura M, Wada H, Marubashi S, Miyamoto A, et al. Clinical and pathological features of Allen's type C classification of resected combined hepatocellular and cholangiocarcinoma: a comparative study with hepatocellular carcinoma and cholangiocellular carcinoma. J Gastrointest Surg 2006;10:987-998

100. Lv P, Lin XZ, Li J, Li W, Chen K. Differentiation of small hepatic hemangioma from small hepatocellular carcinoma: recently introduced spectral CT method. Radiology 2011;259:720-729

101. Alturkistany S, Jang HJ, Yu H, Lee KH, Kim TK. Fading hepatic hemangiomas on multiphasic CT. Abdom Imaging 2012;37:775-780

102. Doo KW, Lee CH, Choi JW, Lee J, Kim KA, Park CM. “Pseudo washout" sign in high-flow hepatic hemangioma on gadoxetic acid contrast-enhanced MRI mimicking hypervascular tumor. AJR Am J Roentgenol 2009;193:W490-W496

103. Yoon SH, Lee JM, So YH, Hong SH, Kim SJ, Han JK, et al. Multiphasic MDCT enhancement pattern of hepatocellular carcinoma smaller than $3 \mathrm{~cm}$ in diameter: tumor size and cellular differentiation. AJR Am J Roentgenol 2009;193:W482-W489

104. Kim B, Byun JH, Kim HJ, Won HJ, Kim SY, Shin YM, et al. Enhancement patterns and pseudo-washout of hepatic 
haemangiomas on gadoxetate disodium-enhanced liver MRI. Eur Radiol 2016;26:191-198

105. Kudo M, Matsui 0, Izumi N, Iijima H, Kadoya M, Imai Y, et al. JSH consensus-based clinical practice guidelines for the management of hepatocellular carcinoma: 2014 update by the Liver Cancer Study Group of Japan. Liver Cancer 2014;3:458-468

106. Taouli B, Koh DM. Diffusion-weighted MR imaging of the liver. Radiology 2010;254:47-66

107. Grazioli L, Federle MP, Brancatelli G, Ichikawa T, Olivetti L, Blachar A. Hepatic adenomas: imaging and pathologic findings. Radiographics 2001;21:877-892; discussion 892894

108. Bioulac-Sage P, Balabaud C, Zucman-Rossi J. Subtype classification of hepatocellular adenoma. Dig Surg 2010;27:39-45

109. Bioulac-Sage P, Laumonier H, Couchy G, Le Bail B, Sa Cunha A, Rullier A, et al. Hepatocellular adenoma management and phenotypic classification: the Bordeaux experience. Hepatology 2009;50:481-489

110. Zucman-Rossi J, Jeannot E, Nhieu JT, Scoazec JY, Guettier C, Rebouissou S, et al. Genotype-phenotype correlation in hepatocellular adenoma: new classification and relationship with HCC. Hepatology 2006;43:515-524

111. Grazioli L, Olivetti L, Mazza G, Bondioni MP. MR imaging of hepatocellular adenomas and differential diagnosis dilemma. Int J Hepatol 2013;2013:374170

112. Katabathina VS, Menias CO, Shanbhogue AK, Jagirdar J, Paspulati RM, Prasad SR. Genetics and imaging of hepatocellular adenomas: 2011 update. Radiographics 2011;31:1529-1543

113. Grazioli L, Bondioni MP, Haradome H, Motosugi U, Tinti R, Frittoli B, et al. Hepatocellular adenoma and focal nodular hyperplasia: value of gadoxetic acid-enhanced MR imaging in differential diagnosis. Radiology 2012;262:520-529

114. Glockner JF, Lee CU, Mounajjed T. Inflammatory hepatic adenomas: characterization with hepatobiliary MRI contrast agents. Magn Reson Imaging 2018;47:103-110

115. Laumonier H, Bioulac-Sage P, Laurent C, Zucman-Rossi J, Balabaud C, Trillaud H. Hepatocellular adenomas: magnetic resonance imaging features as a function of molecular pathological classification. Hepatology 2008;48:808-818

116. Tse JR, Naini BV, Lu DS, Raman SS. Qualitative and quantitative gadoxetic acid-enhanced MR imaging helps subtype hepatocellular adenomas. Radiology 2016;279:118127

117. Guo Y, Li W, Xie Z, Zhang Y, Fang Y, Cai W, et al. Diagnostic value of Gd-EOB-DTPA-MRI for hepatocellular adenoma: a meta-analysis. J Cancer 2017;8:1301-1310

118. Khan AS, Hussain HK, Johnson TD, Weadock WJ, Pelletier SJ, Marrero JA. Value of delayed hypointensity and delayed enhancing rim in magnetic resonance imaging diagnosis of small hepatocellular carcinoma in the cirrhotic liver. J Magn Reson Imaging 2010;32:360-366
119. Grazioli L, Olivetti L, Fugazzola C, Benetti A, Stanga C, Dettori $\mathrm{E}$, et al. The pseudocapsule in hepatocellular carcinoma: correlation between dynamic MR imaging and pathology. Eur Radiol 1999;9:62-67

120. Arrivé L, Fléjou JF, Vilgrain V, Belghiti J, Najmark D, Zins M, et al. Hepatic adenoma: MR findings in 51 pathologically proved lesions. Radiology 1994;193:507-512

121. Agnello F, Ronot M, Valla DC, Sinkus R, Van Beers BE, Vilgrain V. High-b-value diffusion-weighted MR imaging of benign hepatocellular lesions: quantitative and qualitative analysis. Radiology 2012;262:511-519

122. Hussain SM, Terkivatan T, Zondervan PE, Lanjouw E, de Rave $S$, Ijzermans JN, et al. Focal nodular hyperplasia: findings at state-of-the-art MR imaging, US, CT, and pathologic analysis. Radiographics 2004;24:3-17; discussion 18-19

123. Karam AR, Shankar S, Surapaneni P, Kim YH, Hussain S. Focal nodular hyperplasia: central scar enhancement pattern using gadoxetate disodium. J Magn Reson Imaging 2010;32:341344

124. Suh CH, Kim KW, Kim GY, Shin YM, Kim PN, Park SH. The diagnostic value of Gd-EOB-DTPA-MRI for the diagnosis of focal nodular hyperplasia: a systematic review and metaanalysis. Eur Radiol 2015;25:950-960

125. Yoneda N, Matsui 0, Kitao A, Kozaka K, Kobayashi S, Sasaki $M$, et al. Benign hepatocellular nodules: hepatobiliary phase of gadoxetic acid-enhanced MR imaging based on molecular background. Radiographics 2016;36:2010-2027

126. Suh YJ, Kim MJ, Choi JY, Park YN, Park MS, Kim KW. Differentiation of hepatic hyperintense lesions seen on gadoxetic acid-enhanced hepatobiliary phase MRI. AJR Am J Roentgenol 2011;197:W44-W52

127. Mortelé KJ, Praet M, Van Vlierberghe H, Kunnen M, Ros PR. $C T$ and MR imaging findings in focal nodular hyperplasia of the liver: radiologic-pathologic correlation. AJR Am J Roentgenol 2000;175:687-692

128. Brancatelli G, Federle MP, Grazioli L, Golfieri R, Lencioni R. Benign regenerative nodules in Budd-Chiari syndrome and other vascular disorders of the liver: radiologic-pathologic and clinical correlation. Radiographics 2002;22:847-862

129. Asrani SK, Asrani NS, Freese DK, Phillips SD, Warnes CA, Heimbach J, et al. Congenital heart disease and the liver. Hepatology 2012;56:1160-1169

130. Nonomura A, Mizukami Y, Kadoya M. Angiomyolipoma of the liver: a collective review. J Gastroenterol 1994;29:95-105

131. Sherman M. Hepatocellular carcinoma: epidemiology, risk factors, and screening. Semin Liver Dis 2005;25:143-154

132. Altekruse SF, McGlynn KA, Reichman ME. Hepatocellular carcinoma incidence, mortality, and survival trends in the United States from 1975 to 2005. J Clin Oncol 2009;27:14851491

133. Lee SJ, Kim SY, Kim KW, Kim JH, Kim HJ, Lee MG, et al. Hepatic angiomyolipoma versus hepatocellular carcinoma in the noncirrhotic liver on gadoxetic acid-enhanced MRI: a diagnostic challenge. AJR Am J Roentgenol 2016;207:562- 
570

134. Kim R, Lee JM, Joo I, Lee DH, Woo S, Han JK, et al. Differentiation of lipid poor angiomyolipoma from hepatocellular carcinoma on gadoxetic acid-enhanced liver MR imaging. Abdom Imaging 2015;40:531-541

135. Kim YK, Kim CS, Moon WS, Cho BH, Lee SY, Lee JM. MRI findings of focal eosinophilic liver diseases. AJR Am J Roentgenol 2005;184:1541-1548

136. Yoo SY, Han JK, Kim YH, Kim TK, Choi BI, Han MC. Focal eosinophilic infiltration in the liver: radiologic findings and clinical course. Abdom Imaging 2003;28:326-332

137. Lee J, Park CM, Kim KA, Lee CH, Choi JW. MR findings of focal eosinophilic liver disease using gadoxetic acid. Magn Reson Imaging 2010;28:1327-1334

138. Ahn SJ, Choi JY, Kim KA, Kim MJ, Baek SE, Kim JH, et al. Focal eosinophilic infiltration of the liver: gadoxetic acidenhanced magnetic resonance imaging and diffusionweighted imaging. J Comput Assist Tomogr 2011;35:81-85

139. Choi BI, Lee KH, Han JK, Lee JM. Hepatic arterioportal shunts: dynamic CT and MR features. Korean J Radiol 2002;3:1-15

140. Byun JH, Kim TK, Lee CW, Lee JK, Kim AY, Kim PN, et al. Arterioportal shunt: prevalence in small hemangiomas versus that in hepatocellular carcinomas $3 \mathrm{~cm}$ or smaller at twophase helical CT. Radiology 2004;232:354-360

141. Kim TK, Choi BI, Han JK, Chung JW, Park JH, Han MC. Nontumorous arterioportal shunt mimicking hypervascular tumor in cirrhotic liver: two-phase spiral CT findings.
Radiology 1998;208:597-603

142. Motosugi U, Ichikawa T, Sou H, Sano K, Tominaga L, Muhi A, et al. Distinguishing hypervascular pseudolesions of the liver from hypervascular hepatocellular carcinomas with gadoxetic acid-enhanced MR imaging. Radiology 2010;256:151-158

143. Sun HY, Lee JM, Shin CI, Lee DH, Moon SK, Kim KW, et al. Gadoxetic acid-enhanced magnetic resonance imaging for differentiating small hepatocellular carcinomas $(<$ or $=2 \mathrm{~cm}$ in diameter) from arterial enhancing pseudolesions: special emphasis on hepatobiliary phase imaging. Invest Radiol 2010;45:96-103

144. Willatt JM, Hussain HK, Adusumilli S, Marrero JA. MR imaging of hepatocellular carcinoma in the cirrhotic liver: challenges and controversies. Radiology 2008;247:311-330

145. Bialecki ES, Ezenekwe AM, Brunt EM, Collins BT, Ponder TB, Bieneman BK, et al. Comparison of liver biopsy and noninvasive methods for diagnosis of hepatocellular carcinoma. Clin Gastroenterol Hepatol 2006;4:361-368

146. Chernyak V, Santillan CS, Papadatos D, Sirlin CB. LI-RADS ${ }^{\circledR}$ algorithm: CT and MRI. Abdom Radiol (NY) 2018;43:111-126

147. Hope TA, Fowler KJ, Sirlin CB, Costa EA, Yee J, Yeh BM, et al. Hepatobiliary agents and their role in LI-RADS. Abdom Imaging 2015;40:613-625

148. Cha DI, Jang KM, Kim SH, Kang TW, Song KD. Liver Imaging Reporting and Data System on CT and gadoxetic acidenhanced MRI with diffusion-weighted imaging. Eur Radiol 2017;27:4394-4405 